\title{
Análisis de los procesos de transformación territorial en la provincia de Alicante (1985-2011) y su incidencia en el recurso hídrico a través del estudio bibliográfico ${ }^{1}$
}

\author{
María Hernández Hernández \\ Universidad de Alicante. Instituto Interuniversitario de Geografía \\ maria.hernandez@ua.es
}

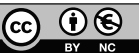

Recepción: febrero de 2012

Aceptación: mayo de 2012

\section{Resumen}

Los municipios litorales de la provincia de Alicante han registrado, en los últimos veinticinco años, notables transformaciones territoriales que se insertan, en gran medida, en las dinámicas de cambio que han caracterizado a la orla litoral mediterránea española. El objetivo de este artículo es poner de manifiesto cómo la comunidad científica ha recogido estos cambios en sus publicaciones prestando una atención especial a las principales temáticas y a los colectivos científicos que las han llevado a cabo.

Palabras clave: análisis bibliográfico; Alicante; agricultura; turismo; agua.

Resum. Anàlisi dels processos de transformació territorial a la provincia d'Alacant (19852011) i la incidència que ha tingut en el recurs hidric a través de l'anàlisi bibliogràfica

Els municipis litorals de la província d'Alacant han registrat, en els últims vint-i-cinc anys, transformacions territorials notables que s'insereixen, en gran mesura, en les dinàmiques de canvi que han caracteritzat l'orla litoral mediterrània espanyola. L'objectiu d'aquest article és posar de manifest com la comunitat científica ha recollit aquests canvis a les seves publicacions i ha prestat una atenció especial a les temàtiques principals i als col-lectius científics que les han dut a terme.

Paraules clau: anàlisi bibliogràfica; Alacant; agricultura; turisme; aigua.

Résumé. Analyse des processus de transformation territoriale dans la province d'Alicante (1985-2011) et leur impact sur les ressources d'eau à travers de l'analyse de la bibliographie

Les communes côtières de la province d'Alicante ont souffert au cours des vingt dernières années d'importantes modifications territoriales, qui sont liés notamment à la dynamique

1. Este artículo se inserta en el proyecto de investigación Modelos de desarrollo territorial y tipologias de consumo de agua potable en espacios turistico-residenciales del litoral alicantino (CSO2009-12772-C03-03), financiado por el Ministerio de Ciencia y Tecnología. 
du changement qui a caractérisé la bande côtière de l'Espagne méditérranéenne. Le but de cet article est de montrer comment la communauté scientifique a ramassée ces changements dans leurs publications, en faissant une attention particulière aux grandes questions et les communautés scientifiques qui ont eu lieu.

Mots clé: analyse de la bibliographie; communes côtières; Alicante; agriculture; tourisme eau.

Abstract. Analysis of Land Change Processes in the Province of Alicante (1985-2011) and their Impact on Water Resources: A Bibliographical Study

In the last twenty-five years, coastal municipalities of the province of Alicante have undergone remarkable territorial changes due largely to the dynamics of change that have characterized the Spanish Mediterranean coastal fringe. The aim of this paper is to show how the scientific community has captured these changes in its publications. Particular attention is paid to the main issues discussed in the literature and the scientific communities that have dealt with them.

Keywords: bibliographical analysis; Alicante; agriculture; tourism; water.

\section{Sumario}

Los procesos de transformación territorial en los municipios litorales de la provincia de Alicante: aproximación metodológica
Los procesos de transformación territorial en los municipios litorales de la provincia de Alicante a través del análisis de la producción científica

Anexo bibliográfico

\section{Los procesos de transformación territorial en los municipios litorales de la provincia de Alicante: aproximación metodológica}

Las obras que a continuación se refieren constituyen una aproximación bibliográfica a los estudios que han abordado la cuestión de las transformaciones territoriales registradas en la provincia de Alicante desde mediados de la década de 1980 hasta la actualidad (2011) y la incidencia que estas dinámicas han tenido, por un lado, en las demandas y los consumos de agua y, por otro, en las políticas orientadas a satisfacer los requerimientos hídricos.

Como su propio nombre indica («aproximación bibliográfica»), no se pretende abarcar todos los trabajos que se han publicado sobre esta materia, puesto que son innumerables y con temáticas muy amplias y diversas, ni recoger tampoco aquéllos que se refieren específicamente a otros espacios geográficos. Se centra básicamente en las relaciones que se establecen entre las actividades económicas dominantes en el ámbito de estudio y su incidencia en los recursos hídricos. Éste se circunscribe a la provincia de Alicante y, más concretamente, a los municipios litorales, dadas las intensas dinámicas de cambio que han interesado a estos territorios en los últimos cincuenta años, particularmente, a partir de la llegada de los caudales del trasvase Tajo-Segura (1978) y, sobre todo, en 
la última década, al amparo de la intensa expansión del turismo residencial. Estas variables determinan que el período objeto de estudio quede circunscrito a los últimos veinticinco años.

Los criterios de selección de las obras para esta recopilación han sido, esencialmente, dos. Por razones obvias, se han incluido todas aquellas contribuciones recogidas en libros, capítulos de libro y artículos que se refieren expresamente en su título o incluyen como "palabras clave» los términos transformaciones territoriales, agricultura, turismo, Alicante, municipios litorales, agua, demanda y consumo de agua, recursos hidricos, recursos convencionales y no convencionales, planificación hídrica y gestión hídrica. Se ha considerado oportuno, asimismo, incluir también aquellas obras que, sin hacer referencia expresa a los términos citados, abordan, sin embargo, la evolución registrada por las actividades económicas (agricultura, turismo y turismo residencial), dadas sus repercusiones sobre el recurso hídrico. No se han contemplado, en cambio, las comunicaciones con o sin publicación presentadas en congresos, seminarios o jornadas, ya que su elevado número, pero sobre todo la amplia gama de escalas (ámbito local, nacional, internacional) y de entes organizadores (universidades, asociaciones vinculadas a comunidades científicas, ayuntamientos, grupos de acción local, etc.) introducía una notable complejidad en la obtención y gestión de los documentos.

Para confeccionar esta compilación, se ha llevado a cabo una búsqueda en bases de datos sociales, concretamente, la del ISOC (CSIC) y, en menor medida, la de SCOPUS, dada la moderada presencia de publicaciones en lengua inglesa. Puntualmente, se han llevado a cabo consultas en otras bases de datos (GEOBASE y REDALyC). Se han examinado, asimismo, las revistas de geografía que publican diversos departamentos universitarios, reunidas en el catálogo de bibliotecas universitarias (REBUIN) y el portal de difusión de producción científica DIALNET. Si bien se ha prestado una atención prioritaria a las publicaciones en materia geográfica, se han considerado también aquéllas llevadas a cabo por otros colectivos universitarios, concretamente, sociólogos, economistas, ingenieros agrónomos y arquitectos. El carácter transversal de las dinámicas socioeconómicas y su incidencia en la demanda de recursos hídricos justifica su inclusión en este análisis bibliográfico.

La explotación de estas fuentes documentales mediante el empleo de una serie de criterios de búsqueda (palabras clave) permitió obtener un listado de publicaciones que fue objeto de un primer proceso de depuración orientado a eliminar, en una primera fase, aquellas entradas que no se adscribiesen a los objetivos de esta investigación. Posteriormente, se procedió a analizar los contenidos de los ítems obtenidos. El sistema de clasificación empleado para agrupar las obras derivadas de la búsqueda en bases de datos se estructura en tres grandes categorías, que corresponden, grosso modo, a los tres aspectos prioritarios de esta investigación, a saber:

a) Análisis de las dinámicas territoriales y su incidencia en las demandas de recursos hídricos. 
b) Planificación y gestión de los recursos disponibles y de las demandas generadas por las dinámicas territoriales.

c) Métodos y técnicas de análisis.

Esta estructura (tabla 1), aunque simple, facilita su análisis, ya que responde a una agrupación básica organizada en torno a tres conceptos. El nivel de heterogeneidad existente en cada uno de ellos obligó a llevar a cabo subdivisiones internas para dar cabida a esa diversidad, sobre todo en la primera de ellas. Si bien la estructura propuesta simplifica la adscripción de las referencias a bloques temáticos, son frecuentes las publicaciones que se adscriben a varias de estas categorías, dadas las interrelaciones que se establecen entre ellas e, incluso más frecuentemente, entre subcategorías. En ese caso, se incluyen en el apartado más genérico y en el que tienen una mayor afinidad de contenidos, con lo cual se evita su inclusión en dos epígrafes y, consiguientemente, su repetición.

$\mathrm{El}$ análisis posterior de las publicaciones adscritas a cada uno de estos apartados puso de manifiesto ciertos argumentos considerados de gran interés para esta publicación, a saber:

a) Identificación de las temáticas de estudio y, sobre todo, la reiteración de éstas para permitir, de este modo, identificar líneas de investigación con continuidad temporal.

b) Acreditar cambios en las materias objeto de estudio al amparo de las transformaciones socioeconómicas y territoriales acaecidas en los últimos veinticinco años.

c) Evidenciar la existencia de colectivos científicos con interés manifiesto en estas materias y si éstos registran cambios en el periodo objeto de análisis.

d) Poner de manifiesto la existencia de investigadores especializados en estos temas y su inserción en unidades de investigación adscritos a determinados centros de investigación.

Cuestiones éstas, a modo de objetivos, que serán objeto de análisis detallado en el epígrafe siguiente. En él, se presentan los resultados más significativos del

Tabla 1. Estructura temática del estudio bibliográfico

I. Repercusiones territoriales de las dinámicas económicas e incidencia en el consumo hídrico:

I.1. Agricultura.

I.2. Turismo sensu stricto.

I.3. Turismo residencial.

II. Planificación y gestión de los recursos y de las demandas hídricas:

II.1. Insuficiencia de recursos. Tensiones y conflictos por el acceso al agua.

II.2. Planificación y gestión de la demanda: recursos convencionales y no convencionales.

III. Métodos y técnicas de análisis.

Fuente: elaboración propia. 
análisis bibliográfico de las publicaciones que examinan las transformaciones territoriales registradas en la provincia de Alicante desde mediados de la década de 1980 hasta la actualidad (2010) y la incidencia que éstas han tenido en las demandas y los consumos de agua. La recopilación bibliográfica se incluye al final del artículo a modo de anexo documental.

\section{Los procesos de transformación territorial en los municipios litorales de la provincia de Alicante a través del análisis de la producción científica}

Las publicaciones obtenidas de la búsqueda en bases de datos bibliográficos se adscriben a tres grandes categorías (tabla 1), que corresponden, grosso modo, con los temas prioritarios de esta investigación.

El primero de los epígrafes, denominado «Repercusiones territoriales de las dinámicas económicas», engloba a aquellos artículos que analizan los dos sectores económicos (agricultura y turismo) que mayores repercusiones han tenido desde el punto de vista de los usos del suelo y de las demandas hídricas. Se diferencia, en este último, entre turismo sensu stricto y turismo residencial, dados los diferentes modelos de implantación territorial y sus requerimientos hídricos. Las publicaciones se centran en las causas que han generado las dinámicas territoriales de manera genérica, pero también su estudio en áreas específicas, entre las que merecen una mención particular comarcas como la Vega Baja del Segura o las dos Marinas, territorios que han registrado las mayores transformaciones territoriales en la provincia de Alicante en los últimos veinticinco años. Su análisis cronológico pone de manifiesto la evolución registrada por las cuestiones objeto de estudio: de investigaciones centradas en las transformaciones agrarias asociadas a la llegada de caudales y el significado del modelo turístico de Benidorm, se pasa, en los últimos tiempos, a un interés creciente por el turismo residencial, al amparo del notable boom urbanístico de la última década y de las cuestiones relacionadas con la insostenibilidad del modelo territorial adoptado.

Las referencias recopiladas en el subepígrafe "Actividades agrarias» (I.1) se caracterizan, desde el punto de vista de las temáticas, por una significativa evolución de las cuestiones objeto de estudio y por el predominio de los estudios realizados por geógrafos y, en menor medida, por economistas y agrónomos. Entre los primeros, las publicaciones de Gil Olcina y Morales Gil constituyen obras de referencia, además de ser origen de un grupo de investigación, Agua y Territorio, que continuará esta línea de trabajo (Rico, Bru, Juárez y Hernández, entre otros). Entre los segundos, cabe citar a los hermanos Melgarejo Moreno. En las publicaciones de las décadas de 1980 y 1990, predominan cuestiones relacionadas con la intensificación de las prácticas agrícolas al amparo de la llegada de los caudales del trasvase Tajo-Segura (1978). A partir de la década de 1990, ésta, sin ser abandonada del todo, deja paso al análisis sobre el valor económico y social de estos regadíos.

Las materias objeto de estudio se articulan en torno a cuatro grandes temas (tabla 2). En el primero, «Paisajes agrarios», se analizan los rasgos que caracte- 
rizan a estos espacios agrícolas antes de la llegada de los caudales procedentes del Alto Tajo y, sobre todo, su incidencia desde el punto de vista de las transformaciones territoriales (conversión de secanos en regadíos y roturación de monte bajo), así como la sustitución de los aprovechamientos propios de una agricultura pluvial por los hortofrutícolas. No es infrecuente que se describan los paisajes característicos antes de la llegada de estos caudales, los particulares sistemas de distribución de los escasos recursos hídricos y de propiedad de las aguas. Publicaciones como las de Gil Olcina (1980, 1985, 1988, entre otras), Vera Rebollo (1984), Costa (1984), Canales y Juárez (1994), Juárez (1983, 1996 y 2004), Bru Ronda (1993) o Morales (1995) resultan ilustrativas. La trascendencia territorial y paisajística de esta transferencia justifica que esa línea de investigación continúe hasta la actualidad, como corroboran publicaciones como la de Melgarejo (2009).

Esta temática evoluciona, a partir de la década de 1990, hacia nuevas líneas de investigación. Entre éstas, cabe mencionar la influencia que, en las actividades agrarias, tiene la llegada de los caudales procedentes del Alto Tajo. Una atención particular reviste el análisis de las repercusiones sociales (en términos de demanda de mano de obra, tanto directa como indirecta), económicas (rentabilidad de los cultivos hortofrutícolas o aportación al producto interior bruto provincial) y territoriales (transformaciones de la red caminera, de los núcleos de población, etc.), inducidas por esta agricultura intensiva, orientada a la exportación y caracterizada por la utilización de técnicas modernas de

Tabla 2. Síntesis de las orientaciones y de las líneas de trabajo en «Actividades agrarias»

\begin{tabular}{|c|c|}
\hline Temas & Líneas de investigación \\
\hline Paisajes agrarios & $\begin{array}{l}\text { - Rasgos definidores de unos paisajes característicos de una agricultura } \\
\text { pluvial. } \\
\text { - Transformaciones paisajísticas asociadas a la llegada de caudales del } \\
\text { trasvase Tajo-Segura. }\end{array}$ \\
\hline Actividades agrarias & $\begin{array}{l}\text { - Influencia en la agricultura de la llegada de caudales procedentes del } \\
\text { - Alto Tajo. } \\
\text { - Nuevos aprovechamientos y sistemas de cultivo. } \\
\text { Repercusiones sociales, económicas y territoriales de la nueva } \\
\text { agricultura. }\end{array}$ \\
\hline Regadíos & $\begin{array}{l}\text { - Rasgos definidores de los nuevos regadíos. } \\
\text { - Demanda agrícola de agua. } \\
\text { - Rentabilidad económica del agua en agricultura. } \\
\text { - Procesos de modernización de los sistemas de regadío. } \\
\text { - Sostenibilidad de los sistemas de regadío. }\end{array}$ \\
\hline $\begin{array}{l}\text { Amenazas sobre } \\
\text { el sector agrícola }\end{array}$ & $\begin{array}{l}\text { - Impactos ambientales derivados de la sobreexplotación de los recursos } \\
\text { hídricos. } \\
\text { - Competencia sobre los recursos del suelo y del agua ejercidas por otras } \\
\text { actividades económicas. } \\
\text { - Abandono de superficies regadas. }\end{array}$ \\
\hline
\end{tabular}

Fuente: elaboración propia. 
cultivo (invernadero y cultivos bajo plástico) y de manejo del agua (riego por goteo). Las publicaciones de Morales (1988, 1996 y 2004), Hernández García et al. (2004) y Rico (2006), entre otras, hacen hincapié en estos elementos. Hernández y Morales (2009 y 2010), además, proporcionan una visión diacrónica acerca de las repercusiones de la llegada de los caudales del trasvase Tajo-Segura en las actividades agrarias tras treinta años de funcionamiento de esta transferencia.

Una tercera línea de investigación, relacionada con la anterior, es la que examina los regadíos. Las publicaciones consideran aspectos relacionados con la demanda agrícola de agua en estas tierras. De igual forma, la rentabilidad económica y social, derivada de la utilización de un metro cúbico de agua en términos de empleo de mano de obra por hectárea y su eficiencia subvencionada (relación entre ayudas de la PAC y consumo de agua) son elementos objeto de estudio por los investigadores, quienes, frecuentemente, comparan estos regadíos con los del interior de España, en los que predominan los cultivos extensivos. Representativas resultan publicaciones como las de Colino y Martínez (2002), Melgarejo y Martínez (2004) o Morales (1994, 2003 y 2005). Ambos temas se relacionan con otra cuestión que ha merecido una gran atención por parte de la comunidad científica, como es la adopción de prácticas orientadas a minimizar los consumos hídricos. El análisis de la incidencia de las políticas orientadas a la modernización de regadíos es objeto de estudio en aportaciones como las de Juárez (1988), Ramón Morte (1994 y 1995), Del Amor y Gil Olcina (2004) o Gómez Espín et al. (2007 y 2011). Los autores inciden en la relevancia de la implementación de sistemas de ahorro de recursos hídricos, pero también en la trascendencia que ésta ha tenido en términos de simplificación y reducción de diversas tareas agrícolas. Vinculadas con esta línea de investigación, en los últimos años, han aparecido nuevas temáticas relacionadas con la necesidad de adoptar modelos de gestión más sostenibles (Juárez, 2008); cuestión ésta relacionada con la escasez de los recursos hídricos, pero también con los nuevos requerimientos de la política agraria comunitaria y la Directiva Marco del Agua.

Un último argumento tiene como objeto de estudio prioritario las amenazas que supone sobre las actividades agrarias, por un lado, la falta de garantía en el suministro y la precariedad de las dotaciones y, por otro, los problemas ambientales derivados de la intensificación de las prácticas agrícolas y, especialmente, sobre los recursos hídricos, de modo que la sobreexplotación de acuíferos es una temática recurrente. También son frecuentes las referencias a los procesos de abandono y desarticulación de espacios regados, como consecuencia, entre otros factores, de la competencia que sobre el agua ejercen los usos urbano-residenciales o la falta de rentabilidad de las actividades agrarias. Significativas resultan publicaciones como Vera y Rico (1996), Gil Olcina (1997), Hernández (1997), Rico y Olcina (2004) y De Gea (2010).

Las referencias recopiladas en el subepígrafe «Turismo sensu stricto» (I.2) se caracterizan, desde el punto de vista de las temáticas, por una continuidad de las cuestiones objeto de estudio y por el predominio de los estudios rea- 
lizados por geógrafos y, en menor medida, por economistas y sociólogos. La publicación de Vera Rebollo (Turismo y urbanización en el litoral alicantino, 1987) marca el inicio de una línea de investigación novedosa en geografía, la de las actividades turísticas. Ésta se prolonga hasta la actualidad por parte de diversos investigadores (Baños, Díez, Ivars, Navalón, Such, Torres, etc.) articulados en torno al grupo de investigación Planificación y Gestión Sostenible del Turismo, dirigido por el mencionado profesor. Las publicaciones llevadas a cabo por geógrafos se completan con las realizadas por los sociólogos Aledo y Mazón, entre otros, integrados en el mencionado grupo de investigación de la Universidad de Alicante.

La materia objeto de estudio se articula en torno a tres grandes temas (tabla 3). El análisis de los rasgos definidores de este modelo turístico y su impronta socioeconómica y territorial fue objeto de análisis a finales de la década de 1980. La ciudad de Benidorm es el ámbito de investigación preferente, al configurarse como un ejemplo de destino especializado en turismo masivo de sol y playa, si bien no se excluye el diagnóstico de otros modelos locales. El examen de los rasgos que definen a este modelo, de las improntas territoriales que genera, de los cambios en los procesos de organización territorial, de la trascendencia socioeconómica de la ciudad de Benidorm o la comparación de este modelo territorial, compacto y en altura, frente a otros más extensivos, son líneas de investigación que continúan hasta la actualidad. Significativas resultan, entre otras, las publicaciones de Vera (1987, 1993 y 2003), Aledo (1994), Aledo y Mazón (1997), Baños (1999), Fernández (2003), Monfort (2002) y Vera e Ivars (2002).

Junto a la temática ya comentada, las publicaciones recopiladas se centran, asimismo, en las relaciones entre este modelo de desarrollo turístico y sus implicaciones en las demandas hídricas. Son frecuentes las obras que analizan las repercusiones del modelo turístico sobre el recurso del agua y las diferencias que se establecen según las tipologías de consumo de la planta hotelera (que se distinguen según categoría y servicios ofertados) o de la oferta complementaria (golf, club náutico, parques de atracciones, etc.). Ambos argumentos permiten

Tabla 3. Síntesis de las orientaciones y de las líneas de trabajo en «Turismo sensu stricto»

\begin{tabular}{ll}
\hline \multicolumn{1}{c}{ Temas } & \multicolumn{1}{c}{ Líneas de investigación } \\
\hline Modelo territorial & - Rasgos definitorios del modelo turístico. Repercusiones \\
& socioeconómicas y territoriales. \\
& - Análisis de modelos locales. Benidorm. \\
\hline Demandas hídricas & - Repercusiones del modelo turístico sobre la demanda hídrica. \\
& - Tipologías de consumo de agua. \\
& - Incidencia del trasvase Tajo-Segura. \\
\hline Estrategias de & - Crisis y agotamiento del modelo. \\
modernización & - Oferta complementaria. \\
& - Planes de modernización. \\
\hline
\end{tabular}

Fuente: elaboración propia. 
contextualizar el significado y el alcance de este sector y la trascendencia del recurso hídrico desde una óptica territorial, económica y social. Las competencias por el acceso al recurso hídrico entre este sector y la agricultura, o más bien su escasez, como condicionante del desarrollo turístico, las particularidades del consumo turístico de agua, las dificultades en los sistemas de abastecimiento y las actuaciones adoptadas para resolverlos o las repercusiones de la llegada de caudales procedentes del Alto Tajo, sintetizada, grosso modo, en la expansión turístico-residencial, al garantizar unos recursos mínimos y de calidad, son otras líneas de investigación prioritarias en el tema «demandas hídricas». Significativas resultan publicaciones como la de Bru (1987), Vera (1988b y 1993b), Vera y Rico (1995), Bengoechea et al. (1999), Vera y Torres (1999), Rico (2007), Rico, Olcina y Sauri (2009) o la de Baños, Vera y Diez (2010).

En los últimos años, las publicaciones recopiladas se adscriben a una tercera línea argumental, a saber, diagnóstico del sector y propuestas de estrategias a adoptar para mejorar su competitividad, dada la competencia ejercida por otros destinos (Caribe, Norte de África o Mediterráneo Oriental). El análisis de iniciativas orientadas a la reestructuración del modelo, la adopción de nuevas estrategias, la implementación de planes de renovación o la creación de oferta complementaria son temas recurrentes en aportaciones como las de Vera, Baños y Cruz (1995), Baños (1998 y 1999), Baños y Torres (1997), Vera y Baños (2010) o Vera, Rodríguez y Capdepon (2011). Línea de investigación que enlaza con las obras en las que, a mediados de la década de 1990, comenzaban a contemplar el agotamiento de este modelo (Vera, 1988a y 1994; Vera y Monfort, 1994).

Las referencias recopiladas en el último epígrafe de este primer apartado (I.3.: «Turismo residencial») son, desde el punto de vista cronológico, las más recientes. Este rasgo viene determinado por la propia temática, a saber, análisis de la construcción de viviendas para uso turístico. Proceso que ha convertido a la Costa Blanca en la última década en uno de los destinos turístico-residenciales más importantes de Europa. Ello explica que, si bien hay publicaciones anteriores como, por ejemplo, las de Gaviria (1976), Vera (1984), Mazón (1987) o Peñin (1988), ésta sea una materia bastante nueva y, sobre todo, con un interés renovado. Esta dinámica territorial es objeto de análisis desde diferentes contextos (socioeconómico, territorial, ambiental e ideológico) y colectivos científicos (geógrafos, sociólogos, economistas, arquitectos y licenciados en ciencias ambientales). De todas ellas, la dimensión ideológica es la que ha suscitado un interés más reciente por parte de la comunidad científica. Pretende, a partir del análisis de claves sociológicas como son los discursos producidos por las elites políticas, los agentes económicos, los expertos o la ciudadanía, comprender las causas que explican los cambios en los modelos urbano-residenciales. Su intensidad, tanto en el tiempo como en el espacio, explica el alcance y la magnitud de los estudios llevados a cabo desde la sociología. El grupo de investigación formado en torno a los profesores Mazón y Aledo, entre los que cabe citar a Huete o Mantecón, refleja el interés creciente por esta temática, que se plasma en numerosas referencias publicadas en los 
últimos cinco años (Huete y Mantecón, 2008; Huete, 2010a; Mantecón, 2004, 2008a y 2010, entre otras). El análisis de los factores que han posibilitado el boom de la construcción y sus consecuencias sociales y territoriales son objeto de estudio por parte de geógrafos alicantinos y valencianos. Representativas resultan las publicaciones de Vera (1987b), Navalón (1995), Olcina y Rico (2005b) o Burriel (2009a y 2009b).

Las materias objeto de estudio se articulan en torno a tres grandes temas argumentales (tabla 4). Al primero, se adscriben aquellas obras que tienen como finalidad poner de manifiesto las características que inciden en la expansión del modelo turístico-residencial (calidad paisajística, bonanza térmica invernal, suelo barato, etc.), los elementos que definen a este sistema urbano (modelo extensivo de baja densidad y predominio de la oferta de alojamiento privado), los rasgos esenciales de la demanda, constituida fundamentalmente por pensionistas procedentes de Europa Occidental, y las consecuencias territoriales, sociales y económicas que este modelo de desarrollo turístico ha tenido en las áreas afectadas. Significativas, entre otras, son las aportaciones de Aledo (2005 y 2008), Rodríguez et al. (2005), Casado (2006) y Burriel (2008). Aspectos a los que hay que unir un planeamiento urbanístico favorable al cambio en la calificación del suelo (Navalón, 1994, 1995 y 2001). Las particulares características que definen al sistema turístico-residencial conducen a diversos autores a cuestionarse si realmente nos encontramos ante un modelo turístico o, en realidad, se trata de un nuevo modelo urbano. Las referencias a «de turistas a residentes», "ni turistas, ni residentes», "de qué se habla al referirnos a turismo residencial» son expresiones que aparecen en muchas de estas publicaciones (García y Schriewer, 2006; Huete, Mantecón y Mazón, 2008; Huete, 2009; Huete y Mantecón, 2010).

$\mathrm{Al}$ considerar las repercusiones generadas por el sistema turístico-residencial, los autores reflexionan sobre los efectos que la llegada masiva de esta población ha tenido en las poblaciones locales. Destacan la configuración de

Tabla 4. Síntesis de las orientaciones y de las líneas de trabajo en «Turismo residencial»

\begin{tabular}{ll}
\hline \multicolumn{1}{c}{ Temas } & \multicolumn{1}{c}{ Líneas de investigación } \\
\hline Modelo territorial & - Elementos definidores del modelo urbano-residencial. \\
& - Factores que inciden en la expansión del modelo residencial. \\
& - Consecuencias territoriales, sociales y económicas de este modelo. \\
& - Imitación del modelo: difusión de los usos residenciales desde la orla \\
& litoral hacia el interior provincial. \\
\hline Demandas hídricas & - Incidencia del modelo residencial en las demandas de agua. \\
& - Rentabilidad social, económica y territorial del recurso hídrico \\
& en el modelo urbano-residencial. \\
\hline Limitaciones & - Limitaciones del modelo urbano-residencial. \\
del sistema & - Insostenibilidad del modelo. \\
& - Conflictos entre usos.
\end{tabular}

Fuente: elaboración propia. 
guetos como resultado de la segregación social entre población autóctona y nuevos residentes y la proliferación de grandes complejos urbano-residenciales al margen de los núcleos poblacionales tradicionales (Alaminos, Santacreu y Albert, 2004; Mantecón, Huete y Mazón, 2009; Mantecón, Huete y Mazón, 2009b). Resaltan, asimismo, los costes sociales, sanitarios especialmente, derivados de la llegada de una población envejecida (Huete, 2010b). Una cuarta línea de investigación en esta primera temática argumental es la que contempla los procesos de difusión urbana desde la orla litoral hacia el interior provincial. Dinámica que se ha apoyado, tal como ponen de manifiesto diversos autores (Giménez y Díez, 2009; Hernández, Moltó y Rico, 2008; Cortés y Espinosa, 2009), en factores como la calidad del paisaje, al asentarse en áreas de media montaña mediterránea, la menor saturación en el interior frente a la costa y el precio inferior del suelo.

Una segunda área temática es la que analiza la incidencia de la difusión del nuevo modelo urbano (la ciudad difusa frente a la tradicional compacta) en los recursos de suelo y agua. En ella, la referencia al incremento de los consumos hídricos, pero también a las actuaciones para contener ese aumento, es una constante. Dinámica que se acrecienta por el espectacular incremento en el censo de viviendas, pero también por la proliferación de zonas ajardinadas y campos de golf. La comparación, en términos de rentabilidad social, económica y territorial, entre este modelo extensivo y el modelo hotelero es frecuente. El, en ocasiones, denostado modelo Benidorm, en gran medida por los impactos visuales, es comparado con el residencial de baja densidad, con lo cual se evidencian los elevados impactos territoriales generados por éste último (gran consumo de recursos hídricos y de suelo) y la baja rentabilidad social y económica, por ejemplo, de un metro cúbico de agua, una vez pagadas las tasas necesarias para la construcción. Representativas resultan publicaciones como las de Vera y Rico (1995), Torres y Hernández (2006), Rico (2007) y Rico, Olcina y Sauri (2009).

Los autores hacen hincapié, asimismo, en los problemas y las limitaciones de este modelo turístico, entre los que cabe citar: la ausencia de planificación, el fuerte impacto ambiental (Cremades, 2009), la insostenibilidad del modelo (Aledo y Mazón, 2005; Burriel, 2009a y 2009b) y los conflictos y las tensiones que se generan entre diversas actividades económicas, fundamentalmente, entre la agricultura y el turismo (Navalón, 2002; Peña et al., 2005). La intensidad, tanto en el tiempo como en el espacio, del proceso es otro de los rasgos que acentúan los conflictos generados por este modelo residencial. Las referencias a términos como tsunami, boom (Gaja, 2008; Burriel, 2009a) o crecimiento con pies de barro (Olcina y Rico, 2005a 2005b) son ilustrativas. La insostenibilidad del modelo es evidenciada a través de la definición y la implementación de numerosos indicadores (Vera e Ivars, 2003a) que se configuran como uno de los métodos de trabajo que mayor interés ha suscitado en la última década.

En el segundo de los epígrafes, titulado «Planificación y gestión de los recursos y las demandas», se analizan, por un lado, las tensiones y los conflictos generados por el acceso al recurso hídrico y, por otro, las actuaciones orientadas 
Tabla 5. Síntesis de las orientaciones y las líneas de trabajo en «Planificación y gestión de los recursos y las demandas"

\begin{tabular}{ll}
\hline \multicolumn{1}{c}{ Temas } & \multicolumn{1}{c}{ Líneas de investigación } \\
\hline Insuficiencia de recursos. & - Recursos disponibles y demandas. Desequilibrios territoriales. \\
Tensiones y conflictos por & - Conflictos por el acceso al recurso hídrico. \\
el acceso al agua (II.1) & - El agua como elemento de desarrollo territorial. \\
\hline Planificación y gestión & - Políticas orientadas a satisfacer la demanda: políticas \\
de la demanda (II.2) & estructurales orientadas al incremento de los recursos \\
& disponibles. Recursos convencionales y no convencionales. \\
& - Políticas orientadas a la satisfacción de la demanda: \\
& ordenación del territorio. \\
& - Sistemas de gestión de los recursos. \\
\hline
\end{tabular}

Fuente: elaboración propia.

a la planificación y la gestión de la demanda (tabla 5). El examen de las obras recopiladas pone de manifiesto, por un lado, la atención que estos argumentos han recibido por parte de diversos colectivos científicos (geógrafos, economistas e historiadores), dada la trascendencia que el agua ha desempeñado en estas sociedades en el tiempo y en el espacio, y, por otro, la evolución en las temáticas de las líneas de investigación al amparo de los cambios normativos que inciden en la gestión y la consideración de los recursos hídricos.

En el primero de los subepígrafes, «Insuficiencia de recursos. Tensiones y conflictos por el acceso al agua (II.1)», diversas publicaciones analizan los desequilibrios territoriales que caracterizan a la Comunidad Valenciana desde el punto de vista de los recursos disponibles y la demanda. Relacionada con este argumento, otra cuestión objeto de análisis frecuente ha sido el examen de las causas que generan el denominado "déficit hídrico» que caracteriza a los municipios litorales de la provincia de Alicante. Los autores hacen mención a las causas físico-climáticas (Bru, 1987; Juárez, 2006; Morales y Gil, 2004), pero, sobre todo, hacen hincapié en el desfase entre recursos y demandas por el notable incremento de éstas desde la segunda mitad del siglo xx (Gil, 2003; Gil y Rico, 2007), como consecuencia de la expansión de las actividades agrícolas y turístico-residenciales. Una segunda línea de investigación, vinculada con la anterior, es la constituida por el análisis de las tensiones y de los conflictos generados entre las actividades económicas por el acceso a un recurso escaso y de calidad (Rico, 2002; Rico y Hernández, 2007; Juárez, Hernández y Rico, 2010); tensiones acentuadas en la última década como consecuencia de la expansión residencial. Por último, deben mencionarse las publicaciones que contemplan la relación que se establece entre el «recurso hídrico» y el «desarrollo económico» (Juárez, 1994 y 2004; Rico, 1997 y 1998; Fuertes y Bengoechea, 2001). Estas líneas de investigación han recibido una atención prioritaria por parte de los geógrafos de la Universidad de Alicante (Gil Olcina, Morales Gil, Rico Amorós, Bru Ronda, Juárez Sánchez Rubio y Hernández Hernández), integrados, en su mayor parte, en el grupo de investigación Agua y Territorio, que se constituyó a finales de la década de 1990, si bien la tra- 
yectoria en esta temática es anterior. Ésta cabe remontarla a la llegada de los profesores Gil Olcina y Morales Gil a la recién creada Universidad de Alicante a finales de la década de 1980 .

En el segundo de los subepígrafes, «Planificación y gestión de la demanda (II.2)», se incluyen aquellas publicaciones que tienen como objeto de estudio las políticas orientadas a incrementar los recursos disponibles para satisfacer las demandas. Las materias objeto de estudio se articulan en torno a tres grandes temas argumentales. En el primero, predominan las obras en las que la satisfacción de éstas se lleva a cabo mediante la construcción de infraestructuras que incrementan los recursos convencionales en una primera fase y, posteriormente, no convencionales (reutilización de aguas residuales y desalación). Representativas son las obras de Gil Olcina (1992 y 1995) y Rico (2002) referentes a las transferencias entre cuencas. Una atención destacada por parte de los investigadores reviste el trasvase Tajo-Segura. Las notables repercusiones territoriales derivadas de la llegada de las aguas procedentes del Alto Tajo a las tierras de las provincias de Almería, Murcia y Alicante van a ser objeto de estudio desde principios de los años ochenta. Desde un punto de vista cronológico, las obras reflejan una evolución significativa en sus argumentos: del análisis de las expectativas creadas por su llegada se pasa a examinar las repercusiones en agricultura, abastecimiento urbano e industria y, por último, a manifestar debilidades y fortalezas (volumen transferido, dependencia, agua de calidad, etc.). Numerosos son los investigadores que, desde ramas de conocimiento diverso (geógrafos, ingenieros, economistas y agrónomos), han centrado sus investigaciones en este trasvase (Morales, 1987 y 1995; Box, 1988; Juárez, 1991; Bautista, 1992; Melgarejo, 2000 y 2009; Claver, 2002; Ezcurra, 2002; Morales, Rico y Hernández, 2005; Ayanz y Plaza, 2009). El estudio de los recursos no convencionales (depuración y desalación) ha sido objeto de atención más reciente, aunque hay precedentes ya a principios de la década de 1990 (Juárez, 1993). Los autores inciden en los factores que motivan su utilización, en la relevancia que estos caudales tienen en estas tierras o en las políticas que han influido en su implementación. Esta área temática ha sido objeto de atención, mayoritariamente, por parte de geógrafos y economistas (Rico, 1996 y 2004; Olcina y Rico, 1998; Olcina 2002a y 2002b; Prats y Melgarejo, 2006; Sauri, Olcina y Rico, 2007; Cánovas y Martínez, 2009).

La satisfacción de las demandas mediante el incremento de los recursos disponibles ha dado paso a una segunda línea argumental, con menor tradición que la anterior, pero con atención creciente en los últimos años, como es la que, basada en la nueva Directiva Marco del Agua (DMA) y en las estrategias de desarrollo sostenible, trata de adecuar demandas y recursos a través de la planificación y la ordenación del territorio. La insostenibilidad del modelo, acentuado por el boom urbanístico, es uno de los argumentos de diversas publicaciones (Vera, 2006; Torres y Hernández, 2006). Una última área temática analiza los sistemas de gestión de los recursos hídricos y, especialmente, el abastecimiento urbano. Una atención prioritaria, por parte de los investigadores, han recibido la Mancomunidad de los Canales del Taibilla (Morales 
y Vera, 1989a y 1989b; Bru, 1995; Morales, 2002; Carrillo, 2002; Olcina y Rico, 2006) y el Consorcio de la Marina Baixa (Rico y Olcina, 2004; Gil Olcina, 2010). Los autores ponen de manifiesto la trascendencia de ambos sistemas públicos de abastecimiento. Del primero, destacan que cuenta con una larga trayectoria y que ha resultado esencial para entender el desarrollo urbano y turístico, no sólo del litoral alicantino, sino también de gran parte de la provincia de Murcia, insistiendo en los resultados obtenidos, pero también en las limitaciones derivadas de la fase expansionista de la última década. Del segundo, que la adopción de diferentes iniciativas (la mayor y mejor regulación de recursos epigeos, la potenciación sostenible de los subterráneos y la reutilización de aguas depuradas) ha permitido optimizar los recursos disponibles y la armonización de los usos; cuestión compleja dado el extraordinario desarrollo turístico y urbano de su franja litoral, que polariza Benidorm.

En el tercer y último epígrafe, "Métodos y técnicas de análisis», se han recopilado aquellas publicaciones cuya finalidad es realizar propuestas dirigidas a formular metodologías orientadas a reconocer las dinámicas territoriales, los impactos de las actividades económicas y su incidencia en los recursos de agua y suelo. Es bastante frecuente que las obras, además de la opción metodológica, la apliquen en áreas específicas y ello dificulta, en ocasiones, su adscripción a uno de los tres epígrafes en los que se ha estructurado este análisis bibliográfico. Si predomina el argumento metodológico, se vincula a este apartado; si domina el análisis de un área concreta, se recoge en el epígrafe temático correspondiente. Es este el caso de publicaciones, por ejemplo, como las llevadas a cabo por el Instituto Universitario de Geografía (1996) o Vera Baños y Jiménez (1995), donde se formulan unos métodos y unas técnicas de trabajo orientadas a la revitalización y la recualificación de los municipios turísticos alicantinos. Su amplia temática determina que haya sido objeto de atención por todos los colectivos científicos que han analizado los procesos de transformación territorial y su incidencia en el consumo de agua.

Las materias objeto de estudio se articulan en torno a dos líneas argumentales. Numerosas aportaciones inciden en la importancia de definir herramientas para valorar el grado de sostenibilidad de los modelos territoriales. Predominan las publicaciones en las que se trata de concretar diferentes indicadores (Vera, 2001; Vera e Ivars, 2003a y 2003b; Juárez, 2004 y 2008) para valorar el grado de transformación que ha registrado este territorio. De las diversas actividades económicas, la que ha recibido una mayor atención es la del turismo residencial, dada la intensa dinámica registrada desde finales del siglo Xx y su incidencia en el recurso hídrico (Rico, 1997; Aledo y Mazón, 1998). Una segunda línea de investigación es aquella cuya finalidad es el análisis y la implementación de técnicas de estudio y diagnóstico del territorio. Éstas, diversas, van desde la utilización de mapas de capacidad de carga hasta los sistemas de información geográfica (Torres, 1995; Aledo et al., 2010; Membrado, 2011). 


\section{Anexo bibliográfico}

\section{Repercusiones territoriales de las dinámicas económicas e incidencia en el recurso hidrico}

\section{I.1. Actividades agrarias}

Amor García, Francisco del y Gil Olcina, Antonio (2004). «Modernización de regadíos y difusión del riego localizado en la Cuenca del Segura». En: GIL Olcina, Antonio (ed.). La cultura del agua en la cuenca del Segura. Murcia: Cajamurcia, 373-402.

BRU Ronda, Concepción (1993). «La agricultura en el Campo de Alicante: Evolución paisajística y reestructuración económica». En: Gil OlCINA, Antonio y Morales GIL, Alfredo (eds.). Medio siglo de cambios agrarios en España. Alicante: Fundación Cultural CAM, 561-578.

Canales Martínez, Gregorio y Juárez Sánchez Rubio, Cipriano (1988). «Transformaciones agrarias indicativas y planificación urbanística». Estudios Geográficos, 49 (193), 581-602.

- (1994). «Nuevos regadíos en el secano del Bajo Segura: el modelo referencial de San Onofre-Torremendo (1953-1992)». Investigaciones Geográficas, 11, 215-238.

Colino Sueira, José y Martínez Paz, José María (2002). «El agua en la agricultura del Sureste español: productividad, precio y demanda». En: García Álvarez CoQue, José María (coord.). La agricultura mediterránea en el siglo XX. Almería: Fundación Cajamar, 199-222.

Costa Más, José (1984). «La agricultura de los cosechero-exportadores de tomate de invierno en Alicate». Investigaciones Geográficas, 2, 63-86.

Gea Calatayud, Manuel de (2010). «La huerta histórica del Bajo Segura: Algunas claves sobre su formación, gestión del agua y situación e impactos actuales». Revista Valenciana d'Etnologia, 5, 55-70.

Gil Olcina, Antonio (1980). «Paisajes rurales en la fachada este de España». En: AAVV. Los paisajes rurales de España. Madrid: Asociación de Geógrafos Españoles, 249-266.

- (1985). «La propiedad del agua en los grandes regadíos deficitarios del sureste peninsular: el ejemplo del Guadalentín». Agricultura y Sociedad, 35, 203-231.

- (1986). «Paisajes rurales». El Campo, 103., 61-67. [Ejemplar dedicado a la Comunidad Valenciana]

- (1988). «Evolución de los grandes regadíos deficitarios del Sureste Peninsular». En: Gil Olcina, Antonio y Morales Gil, Alfredo (eds.). Demanda y economía del agua en España. Alicante: Universidad de Alicante, 331-327.

- (1990). «Riegos mediante elevación de aguas superficiales en la fachada este de España». Estudios Geográficos, 51 (199-200), 453-468.

- (1997). «Agua y agricultura: transformaciones recientes, problemas ambientales y socioeconómicos». Geographicalia, 34, 69-99.

- (2002). Los regadios de la cuenca del Segura: una visión histórica. Madrid: Ministerio de Medio Ambiente y Confederación Hidrográfica del Segura.

Gómez Espín, José María; García Marín, Ramón y Gil Meseguer, Encarnación (2007). «Modernización de regadíos con aguas subterráneas en ámbitos semiáridos». $M+A$, revista electrónica de medio ambiente, 3, 1-23.

Gómez Espín, José María; López Fernández, José Antonio y Montaner Salas, María Encarnación (coords.) (2011). Modernización de regadios, sostenibilidad social y económica: La singularidad de los regadios del trasvase Tajo-Segura. Murcia: Universidad de Murcia. 
Gómez López, José Daniel (1991). «El comercio detallista de flor cortada y planta ornamental en la Comunidad Valenciana». Investigaciones Geográficas, 9, 203-214.

Hernández García, Francisco; Legua Murcia, Pilar y Melián Navarro, Amparo (2004). «Influencia del PHN en el empleo agrario de la provincia de Alicante». En: Melgarejo Moreno, Joaquín (ed.). Repercusiones socioeconómicas del Plan Hidrológico Nacional en la provincia de Alicante. Alicante: COEPA, 147-162.

Hernández Hernández, María (1997). Paisajes agrarios y medio ambiente en Alicante: Evolución e impactos medioambientales en los paisajes agrarios alicantinos, 19501995. Alicante: Universidad de Alicante.

Hernández Hernández, María y Morales Gil, Alfredo (2008). «Transcendencia socio-económica del trasvase Tajo-Segura tras 30 años de su funcionamiento en la provincia de Alicante». Investigaciones Geográficas, 46, 31-48.

- (2009). «La hortofruticultura y las aguas del trasvase Tajo-Segura: repercusiones socioeconómicas». En: Melgarejo Moreno, Joaquín (dir.). El Trasvase TajoSegura: Repercusiones económicas, sociales y ambientales en la cuenca del Segura. Alicante: CAM Cultural, 413-464.

- (2010). «Repercusiones sociales del trasvase Tajo-Segura: El empleo agrícola en la provincia de Alicante». En: Melgarejo Moreno, Joaquín y Molina GiméNEZ, Andrés (eds.). Incidencia del trasvase Tajo Segura en la provincia de Alicante. Alicante: Fundación COEPA para la Formación. [CD]

Hernández Hernández, María; Rico Amorós, Antonio Manuel y Olcina Cantos, Jorge (2010). «Los regadíos del Vinalopó (Alicante)». En: Hermosilla Pla, Jorge (dir.). Los regadios históricos españoles: Paisajes culturales, paisajes sostenibles. Madrid: Ministerio de Medio Ambiente, Medio Rural y Marino, 285-306.

JuÁrez SÁnchez Rubio, Cipriano (1983). «Utilización agraria del suelo en las comarcas de la provincia de Alicante». Investigaciones Geográficas, 1, 67-86.

- (1988). "Mejoras técnicas en el regadío alicantino: disminución del consumo y aumento de la productividad». En: Gil Olcina, Antonio y Morales Gil, Alfredo (eds.). Demanda y economía del agua en España. Alicante: Universidad de Alicante, 390-402.

- (1994). "Contrastes internos en la producción agraria de Alicante». En: CABERo DiÉGuez, Valentín (ed.). El medio rural español: cultura, paisaje y naturaleza: Homenaje a Don Ángel Cabo Alonso, vol. II. Salamanca: Universidad de Salamanca, 689-698.

- (1996). «Aumento de recursos de agua: nuevas tecnologías y repercusión socioeconómica en la Vega Baja y Bajo Vinalopó». Investigaciones Geográficas, 15, 61-77.

- (2004). «Asignación de recursos de agua para uso agrario y crecimiento económico en la comarca meridional agraria de Alicante». Revista Española de Estudios Agrosociales y Pesqueros, 202, 135-166.

- (2008a). «Avance y repercusión del regadío sostenible en las zonas rurales de Alicante: reto y oportunidades». Investigaciones Geográficas, 45, 29-61.

- (2008b). "Sustainable irrigation in areas with an arid and semi-arid climate in the province of Alicante». En: Villacampa, Yolanda; Brebbia, Carlos y Prats, Daniel (eds.). Sustainable irrigation: Management, Technologies and Policies. Southampton: WIT Press, 223-233.

- (2010). «La agricultura y el problema del agua en la provincia de Alicante». En: Segrelles Serrano, José Antonio (coord.). A vueltas con la agricultura: Una actividad económica necesaria y marginada. Alicante: Instituto de Cultura Juan Gil-Albert, 105-130. 
Juárez Sánchez Rubio, Cipriano y Vera Rebollo, José Fernando (1984). «Repercusión económica por cambio de uso y propiedad del agua en el litoral oriolano». Investigaciones Geográficas, 2, 139-148.

Juárez Sánchez Rubio, Cipriano; Ponce Herrero, Gabino; Ramón Morte, Alfredo y Canales Martínez, Gregorio (1993). «Las agriculturas alicantinas». En: Pedreño, Andrés (dir.). Estructura económica de la provincia de Alicante. Alicante: Diputación Provincial, 147-171.

López Gómez, Antonio (1986). "Huertas tradicionales, campos regados y nuevas transformaciones». El Campo, 103., 57-60. [Ejemplar dedicado a la Comunidad Valenciana]

López Ortiz, María Inmaculada y Melgarejo Moreno, Joaquín (2007). «El fin del regadío tradicional y la creación de sociedades mercantiles para la venta del agua: Riegos de Levante Margen Derecha del Segura». Boletín de la Asociación de Geógrafos Españoles, 43, 307-334.

Melgarejo Moreno, Pablo (2009). «Influencia económica del trasvase Tajo-Segura en la agricultura de las provincias de Murcia, Alicante y Almería». En: Melgarejo Moreno, Joaquín (dir.). El trasvase Tajo-Segura: repercusiones económicas, sociales y ambientales en la cuenca del Segura. Alicante: CAM, 345- 411.

Melgarejo Moreno, Pablo; Martínez Nicolás, Juan José y Martínez Tome, Juan (2004). «Productividad y rentabilidad del agua de riego en la provincia de Alicante». En: Melgarejo Moreno, Joaquín (ed.). Repercusiones socioeconómicas del Plan Hidrológico Nacional en la provincia de Alicante. Alicante: COEPA, 103-143.

Morales Gil, Alfredo (1988). «Usos competitivos del agua en la cuenca del Segura». Investigaciones Geográficas, 6, 103-110.

- (1994). «Demandas y usos del agua en España». Boletín de la Asociación de Geógrafos Españoles, 18, 3-18.

- (1995). "Huertas tradicionales, nuevos regadíos y medio ambiente en el valle del Segura». En: García Fernández, Jesús (ed.). Medio ambiente y desarrollo rural. Valladolid: Fundación Duques de Soria, 131-158.

- (1996). «Escasez y rentabilidad del agua en el sureste de España: agricultura de vanguardia». En: García Fernández, J. (ed.). Medio ambiente y crisis rural. Valladolid: Fundación Duques de Soria, 131-157.

- (1997). Aspectos geográficos de la horticultura de ciclo manipulado en España. Alicante: Universidad de Alicante.

- (1998). "Rareté et rentabilité de l'eau dans le sud-est de l'Espagne: l'agriculture d'avant-garde». Territoires en Mutation, 3, 117-132.

- (1999). "El consumo agrícola de agua: sus modalidades y trascendencia socioeconómica actual». En: Gil Olcina, Antonio y Morales Gil, Alfredo (eds.). Los usos del agua en España. Alicante: Caja de Ahorros del Mediterráneo, 49-78.

- (2002). «Rentabilidad del agua para usos agrarios». En: Gil Olcina, A. y Morales Gil, Alfredo (eds.). Insuficiencias hidricas y Plan Hidrológico Nacional. Alicante: Servicio de Publicaciones de la Universidad de Alicante, 149-178.

- (2003). «Eficiencia de los regadíos españoles». Cuadernos de Geografía, 73-74, 323-342.

- (2004). «Luz, temperatura, viento y humedad, factores básicos para la localización de la horticultura de ciclo manipulado en España». En: AAVV. Historia, clima y paisaje: Estudios geográficos en memoria del profesor Antonio López Gómez. Valencia: Universidad de Valencia, 529-538. 
- (2004). «Horticultura de ciclo manipulado y citricultura selecta». En: Gil Olcina, Antonio y Morales Gil, Alfredo (eds.). Aridez, salinización y agricultura en el sureste ibérico. Murcia: Centro de Estudios Ramón Areces, 36-68.

- (2005). «La demanda agrícola de agua en España: aspectos socioeconómicos». En: Demanda y consumo de agua en el dominio mediterráneo. Mallorca: Fundación Ramón Areces y Club Última Hora, 38-41.

Morales Gil, Alfredo y Bru Ronda, Concepción (1984). «Disponibilidades hídricas y modernas técnicas de embalse en el Campo de Alicante». Investigaciones Geográficas, 2, 19-50.

Morales Gil, Alfredo y Hernández Hernández, María (2010). «Mutaciones de los usos del agua en la agricultura española durante la primera década del siglo xxI». Investigaciones Geográficas, 51, 27-51.

Morales Gil, Alfredo y Juárez Sánchez Rubio, Cipriano (1981). «Cambio en los usos del agua». Estudios Geográficos, 42 (165), 375-396.

Morales Gil, Alfredo; Olcina Cantos, Jorge y Rico Amorós, Antonio Manuel (2001). "Regadíos intensivos». En: Romero González, Joan; Morales Gil, Alfredo; Vera Rebollo, José Fernando (eds.). La Periferia emergente: La Comunidad Valenciana en la Europa de las Regiones. Barcelona: Ariel, 325-342.

Ramón Morte, Alfredo (1994). "Aplicación del riego localizado y economía del agua en la modernización de la agricultura valenciana». Boletín de la Asociación de Geógrafos Españoles, 18, 97-100.

- (1995). Tecnificación del regadio valenciano: Análisis territorial de la difusión del sistema de riego localizado. Madrid: MAPA. Serie Estudios, 85.

Rico Amorós, Antonio Manuel (2006). «Políticas agrarias, eficiencia económica y retos de futuro en los regadíos intensivos». Boletín de la Asociación de Geógrafos Españoles, 41, 113-149.

Rico Amorós, Antonio Manuel y Morales Gil, Alfredo (2003). «Las actividades productivas actuales: regadíos hortícolas y frutícolas». En: Morales Gil, Alfredo (coord.). Cultura, paisajes y sociedades en el eje de desarrollo territorial del Bajo Segura y Campo de Cartagena. Madrid: AUSUR y Ministerio de Fomento, 221-247.

Rico Amorós, A.M. y Olcina Cantos, J. (2004). «Ventajas, dependencias, incertidumbres y riesgos de la agricultura de vanguardia en España». En: Gil Olcina, Antonio y Morales Gil, Alfredo (eds.). Aridez, salinización y agricultura en el sureste ibérico. Murcia: Fundación Ramón Areces e Instituto Euromediterráneo de Hidrotecnia, 175-255.

Romero GonzÁlez, Joan (1993): La agricultura valenciana en el proceso de industrialización y urbanización. Valencia: Generalitat Valenciana. Serie Estudios.

Romero González, Joan y Tortosa Pastor, Francisco (1991). «El regadío». En: Atlas de la Comunidad Valenciana. Alicante: Prensa Alicantina, 501-520.

Sumpsi, José María (2001). «La economía del agua en la agricultura: incidencia en la agricultura mediterránea». Revista del Instituto de Estudios Económicos, 4, 367-384.

Vera Rebollo, José Fernando (1984). Tradición y cambio en el campo del Bajo Segura. Alicante: Instituto de Estudios Alicantinos.

- (1986). «Riegos localizados y cultivos de invernadero». El Campo, 103., 50-53. [Ejemplar dedicado a la Comunidad Valenciana]

- (1993). "Procesos de transformación y crisis en la agricultura del litoral alicantino». En: Gil Olcina, Antonio y Morales Gil, Alfredo (eds.). Medio siglo de cambios agrarios en España. Alicante: Diputación Provincial de Alicante, 463-484. 
Vera Rebollo, José Fernando y Rico Amorós, Antonio Manuel (1996). «El problema del agua en la Huerta de Alicante». En: Alberola Roma, Armando (ed.). Cuatro siglos de técnica hidráulica en tierras alicantinas. Alicante: Instituto de Cultura Juan Gil-Albert, 43-65.

\section{I.2. Turismo sensu stricto}

Aledo Tur, Antonio (1994). «Un modelo turístico para ciudades de tamaño pequeño: La industria turística en la Costa Blanca y su adaptación a la nueva sociedad postindustrial». Estudios Turísticos, 121, 83-90.

Baños Castiñeira, Carlos Javier (1998). «La oferta turística complementaria en los destinos turísticos alicantinos: Implicaciones territoriales y opciones de diversificación». Investigaciones Geográficas, 19, 85-103.

- (1999). "Modelos turísticos locales. Análisis comparado de dos destinos de la Costa Blanca». Investigaciones Geográficas, 21, 35-77.

- (2000). «Actividades y áreas turísticas: La oferta de alojamiento turístico». En: GIL Olcina, Antonio (dir.). Cartografía temática de las tierras alicantinas. Alicante: Servicio de Publicaciones de la Universidad de Alicante, 112-115.

Baños Castiñera, Carlos Javier y Torres Alfosea, Francisco José (1997). «Accroisement touristique et modèles territoriaux en crise: Des propositions pour la competitivité». En: CRISTEA, V. (coord.). L'Espace rural: Approche pluridisciplinaire. Risoprint, 159-167.

Baños Castiñeira, Carlos Javier; Vera Rebollo, José Fernando y Díez Santo, Daniel (2010). «El abastecimiento de agua en los espacios y destinos turísticos de Alicante y Murcia». Investigaciones Geográficas, 51, 81-105.

Bengoechea Morancho, Aurelia; Rubert Nebot, Juan José y Fuertes Eugenio, Ana María (1999). "Turismo y disponibilidad de recursos hídricos: el caso de Benidorm». Papers de Turisme, 26, 28-47.

BRU Ronda, Concepción (1987). «El turismo y el problema de abastecimiento de agua en el litoral alicantino". Canelobre, 10, 70-74

Bru Ronda, Concepción y Santafé Martínez, José María (1995). Agua y espacios de ocio. Alicante: Universidad de Alicante.

Claver Cortés, Enrique; Molina Azorín, José Francisco y Pereira Moliner, Jorge (2007). "Competitividad en turismo de masas». Annals of Tourism Research, 9 (2), 266-286.

Cutillas Orgilés, Ernesto (2009). «El espacio social de Torrevieja en el contexto geodemográfico valenciano». Boletín de la Asociación de Geógrafos Españoles, 49, 209-236.

Fernández Galiano, Luís (2003). «Benidorm en positivo: El turismo intensivo de los rascacielos». Arquitectura y Vivienda, 99-100, 178-181.

Gozálvez Pérez, Vicente; Larrosa Rocamora, Juan Antonio; Martín Serrano, Gabino; Palazón Ferrando, Salvador y Ponce Herrero, Gabino (2005). «Les territoires du tourisme litorel et les pouvoirs locaux dans la province d'Alicante (Espagne)». Rives Méditerranéennes, 20.

Hernández Hernández, María (2007). «Il turismo nella Comunidad Valenciana spagnola. Un caso di studio: la Costa Blanca». En: BAtTigelli, Franca (ed.). Turismo $e$ ambiente nelle aree costiere del mediterraneo: Regioni a confronto. Udine: Forum Editrice, 99-126.

IRIBAS SÁNCHEZ, José María (1996). «Consideraciones sobre la situación urbana y turística del litoral alicantino». En: Bru Ronda, Concepción y Santafé MartíNEZ, José María (eds.). Agua y espacios de ocio. Alicante: CAM, 61-98. 
JuÁrez SÁnchez Rubio, Cipriano (1990). «Situación y perspectiva del abastecimiento de agua en los municipios turísticos del litoral alicantino». En: Vera Rebollo, J. F. (dir.). Libro blanco del turismo en la Costa Blanca II: Estructura territorial y urbanistica. Alicante: Cámara Oficial de Comercio, Industria y Navegación de Alicante, 101-118.

Martí Ciriquian, Pablo y García Mayor, María Clara (2008): «Tourism in Alicante: developments from the 60's to the present day». En: Exploring the public city. Alicante: Universidad de Alicante, 62-67.

Mazón, Tomás y Aledo, Antonio (dirs.) (1997). Bajo Segura: el sector turístico. Alicante: Patronato Provincial de Turismo de la Diputación de Alicante.

Melgarejo Moreno, Joaquín (ed.) (2010). Incidencia del trasvase Tajo-Segura en el sector turístico alicantino. Alicante: Fundación COEPA.

Monfort Mir, Vicente María (2000). «Recursos y capacidades de la hotelería de litoral: Benidorm y Peñíscola». Estudios Turísticos, 143, 25-63.

- (2002). «Estrategia competitiva y desempeño en la industria hotelera costera: evidencias empíricas en Benidorm». Cuadernos de Turismo, 10, 7-42.

Pedreño, Andrés (dir.). El turismo en la Costa Blanca. Alicante: Cámara Oficial de Comercio, Industria y Navegación de Alicante.

Ponce Herrero, Gabino; Ramón Morte, Alfredo; Vera Rebollo, José Fernando y DÁvila Linares, Juan Manuel (1990). «Evaluación del grado de especialización turística de los municipios litorales valencianos». Investigaciones Geográficas, 8, 83-112.

Rico Amorós, Antonio Manuel (2004). «Sequías y abastecimientos de agua potable en España». Boletín de la Asociación de Geógrafos Españoles, 37, 137-181.

- (2007). "Tipologías de consumo de agua en abastecimientos urbano-turísticos de la Comunidad Valenciana». Investigaciones Geográficas, 42, 5-34.

Rico Amorós, Antonio Manuel y Olcina Cantos, Jorge (2002). «Systèmes de gestion et d'aprovisionnement en eau potable dans les municipalités touristiques de la Costa Blanca (Alicante)». En: Politiques de l'eau. Madrid: Servicio de Publicaciones de la Casa de Velázquez, 89-102.

Rico Amorós, Antonio Manuel; Olcina Cantos, Jorge y Sauri, David (2009). "Tourist land use patterns and water demand: Evidence from the Western Mediterranean». Land Use Policy, 26 (2), 493-501.

Such Climent, María de la Paz (2000). Turismo y medio ambiente en la Comunidad Valenciana. Alicante: Servicio de Publicaciones de la Universidad de Alicante.

Torres Alfosea, Francisco José (1997). Ordenación del litoral en la Costa Blanca. Alicante: Universidad de Alicante.

Torres Alfosea, Francisco José y Vera Rebollo, José Fernando (2002). «El litoral de la Comunidad Valenciana». En: Romero, Joan; Morales Gil, Alfredo y Vera ReboLLO, José Fernando (coords.). Comunidad Valenciana. Barcelona: Ariel, 197-203.

Vera Rebollo, José Fernando (1987a). Turismo y urbanización en el litoral alicantino. Alicante: Instituto de Estudios Juan Gil-Albert.

- (1987b). «Modelos de ocupación del suelo y dominación territorial en los municipios turísticos alicantinos». Canelobre, 10, 64-68.

- (1988a). «Crisis del poblamiento turístico en el litoral mediterráneo español». Urbanismo: Revista Oficial del Colegio de Arquitectos de Madrid, 5, 6-10.

- (1988b). «Los recursos hídricos como factor condicionante del desarrollo turístico en el litoral alicantino». En: Gil Olcina, Antonio y Morales Gil, Alfredo (eds.). Demanda y economía del agua en España. Alicante: Universidad de Alicante, 115-124. 
- (1990). «La fachada este de España: Transformaciones estructurales en el contexto de un gran eje de actividad económica». Boletín de la Asociación de Geógrafos Españoles, 11, 67-88.

- (1993a). «La dimensión ambiental de la planificación turística: una nueva cultura para el consumo turístico». Papeles de Geografía, 18, 195-204.

- (1993b). «Relaciones entre la implantación turística y el espacio agrario del litoral survalenciano". Papers de Turisme, 11, 7-32.

- (1994). «El modelo turístico del Mediterráneo español: agotamiento y estrategias de reestructuración». Papers de Turisme, 14-15, 131-148.

- (2003). «Desarrollo turístico y procesos de reorganización territorial». En: MorALES GIL, Alfredo (coord.). Nuevas dinámicas de desarrollo y ejes de integración territorial: Campo de Cartagena y Bajo Segura. Murcia: AUSUR y Ministerio de Fomento, 247-272.

- (2006). "Agua y actividades turísticas: la necesaria sostenibilidad en la gestión de los recursos». En: IbáÑez Martí, C. y Prats Fornells, N. (eds.). Ciencia, técnica y ciudadanía, claves para una gestión sostenible del agua. Zaragoza: Fundación Nueva Cultura del Agua, 381-398.

Vera Rebollo, José Fernando y Baños Castiñeira, Carlos Javier (1999). «Del crecimiento a las implicaciones territoriales de la diversificación turística en España». En: AAVV. Professor Joan Vilà Valentí: el seu mestratge en la geografia universitària. Barcelona: Universitat de Barcelona, 1.405-1.432.

- (2001) «Actividad y espacios turísticos». En: Romero GonzÁlez, Joan; Morales Gil, Alfredo y Vera Rebollo, José Fernando (coords.). La periferia emergente: La Comunidad Valenciana en la Europa de las Regiones. Barcelona: Ariel, 373-395.

- (2004). "Turismo, territorio y medio ambiente: La necesaria sostenibilidad». Papeles de Economía Española, 102, 271-286.

- (2010). «Renovación y reestructuración de los destinos turísticos consolidados del litoral: las prácticas recreativas en la evolución del espacio turístico». Boletín de la Asociación de Geógrafos Españoles, 53, 329-353.

Vera Rebollo, José Fernando; Baños Castiñeira, Carlos Javier y Cruz Orozco, Jorge (1995). «Turismo y organización del territorio: desajustes de un modelo de implantación y nuevas estrategias». Cuadernos de Geografía, 58, 439-471.

Vera Rebollo, José Fernando; Casado Díaz, María de los Ángeles y Ramón RodríGuEZ, Ana Belén (2009). "Consideraciones sobre el impacto del Plan Hidrológico Nacional en el sector turístico de la provincia de Alicante». En: Melgarejo MoreNO, Joaquín (ed.). Repercusiones socio-económicas del Plan Hidrológico Nacional en la provincia de Alicante. Alicante: COEPA, 251-268.

Vera Rebollo, José Fernando e Ivars Baidal, Josep Antoni (2002). «Turismo, territorio y desarrollo regional en la Comunidad Valenciana». En: Blanquer Criado, David (coord.). Ordenación y gestión del territorio turístico. Valencia: Tirant Lo Blanch, 152-192.

Vera Rebollo, José Fernando y Monfort Mir, Vicente María (1994). «Agotamiento de modelos turísticos clásicos. Una estrategia territorial para la cualificación: La experiencia para la Comunidad Valenciana». Estudios Turisticos, 123, 17-46.

Vera Rebollo, José Fernando y Rico Amorós, Antonio Manuel (1995). «Los sistemas de abastecimiento de agua potable en un espacio turístico y residencial: la Costa Blanca». En: Bru Ronda, Concepción y Santafé Martínez, José María (eds.). Agua y espacios de ocio. Alicante: Universidad Internacional Menéndez Pelayo y Fundación CAM, 105-150. 
Vera Rebollo, José Fernando; Rodríguez Sánchez, Isabel y Capdepon Frías, Margarita (2011). «Reestructuración y competitividad en destinos maduros de sol y playa: la renovación de la planta hotelera de Benidorm». En: López, Diego (coord.). Renovación de destinos turísticos consolidados. Valencia: Tirant Lo Blanch, 41-68.

Vera Rebollo, José Fernando y Torres Alfosea, Francisco José (1999). «Peculiaridades y tendencias en el gasto turístico del agua». En: Gil Olcina, Antonio y Morales Gil, Alfredo (eds.). Los usos del agua en España. Alicante: Universidad de Alicante y CAM, 161-202.

\section{I.3. Turismo residencial}

Alaminos, Antonio; Santacreu, Oscar y Albert, María del Carmen (2004). Los procesos de aculturación y socialización de extranjeros en Alicante. Alicante: OBETS.

Alcaraz Ramos, Manuel (2005). Alicante especulación. Alicante: Club Universitario.

Aledo Tur, Antonio (2005). "Los otros inmigrantes: residentes europeos en el sudeste español». En: García Jiménez, Modesto y Fernández Rufete, José (coords.). Movimientos migratorios contemporáneos. Murcia: Universidad Católica de Murcia, 61-180.

- (2008). «De la tierra al suelo: la transformación del paisaje y el nuevo turismo residencial». Arbor: Ciencia, Pensamiento y Cultura, 729, 99-113.

Aledo Tur, Antonio y Mazón Martínez, Tomás (2005). «Los límites del turismo residencial: el caso de Torrevieja». Estudios Turísticos, 165, 77-96

Aledo, Antonio; Ortiz, Guadalupe y García Andreu, Hugo (2008). «Análisis estructural del sistema turístico residencial en la Costa Blanca». Investigaciones Geográficas, 46, 89-106.

Burriel de Orueta, Emilio (2008). «La “década prodigiosa” del urbanismo español (1997-2006)». Scripta Nova. Revista Electrónica de Geografía y Ciencias Sociales, vol. XII, 270 (64).

- (2009a) «Los límites del planeamiento urbanístico municipal: El ejemplo valenciano». Documents d'Anàlisi Geogràfica, 54, 33-54.

- (2009b). "La planificación territorial en la Comunidad Valenciana (1986-2009)». Scripta Nova: Revista Electrónica de Geografía y Ciencias Sociales, vol. XIII, 306.

Casado Díaz, María de los Ángeles (2001). De turistas a residentes: La migración internacional de retirados en España. Alicante: Universidad de Alicante.

- (2006). "Retiring to Spain: an analysis of differences among north European Nations». Journal of Ethnic and Migration Studies, 32 (8), 1.321-1.339.

Cortés, Carlos y Espinosa, Ana (2009). «Cambio de residencia desde las zonas litorales hacia los municipios rurales de la Montaña de Alicante: Motivaciones y condiciones de vida de la población jubilada europea». En: López TRIGAL, Lorenzo y Abellán, Antonio (eds.). Envejecimiento, despoblación y territorio. León: Universidad de León, 137-147.

CREMADEs Rodera, Roger (2009): Macrourbanisme i agressions al paisatge mediterrani: El medi ambient $i$ la societat valenciana. Valencia: Riu Blanc.

Díaz Orueta, Fernando y Lourés Seonne, María Luisa (2008). «La globalización de los mercados inmobiliarios: su impacto sobre la Costa Blanca». Ciudady Territorio. Estudios Territoriales, 155, 77-92.

Gaja, Fernando (2001). «La producción de suelo urbanizable como objeto de la actuación urbanística». Urban, 5, 83-101.

- (2008). «El "tsunami urbanizador" en el litoral mediterráneo: El ciclo de hiperproducción inmobiliaria 1996-2006». Scripta Nova: Revista Electrónica de Geografía y Ciencias Sociales, vol. XII, 270 (66). 
García, Modesto y Schriewer, Klaus (eds.) (2006). Ni turistas ni migrantes: Movilidad residencial europea en España. Murcia: Isabor.

Gaviria, Manuel (1976). El turismo de invierno y el asentamiento de extranjeros en la provincia de Alicante. Alicante: Diputación Provincial.

Gili i Fernández, Mercè (2003). «Las viviendas de segunda residencia, ¿̇ocio o negocio?». Scripta Nova, VII (146).

Giménez Font, Pablo y Díez, Daniel (2009). «Contexto rural y crecimiento urbanístico en el traspaís de Benidorm: Un análisis crítico del modelo de desarrollo territorial». En: Feria, José María y Ojeda, Juan Francisco (eds.). Territorios, sociedades y políticas. Sevilla: Universidad Pablo de Olavide, 275-285.

Gómez Ordoñez, José Luís; Navarro Vera, José Ramón y Martí Ciriquian, Pablo (2004). La construcción del territorio litoral. Alicante: Universidad de Alicante.

GonzÁlez Reverté, Francesc (2008). «El papel de los destinos turísticos en la transformación socio-demográfica del litoral mediterráneo español». Boletín de la Asociación de Geógrafos Españoles, 47, 79-107.

Hernández Hernández, María; Moltó Mantero, Enrique y Rico Amorós, Antonio Manuel (2008). «Las actividades turístico-residenciales en las montañas valencianas». Ería, 75, 77-97.

Huete, Raquel (2005). «Factores de atracción de Alicante como destino residencial: El punto de vista de los residentes europeos». En: Mazón, Tomas y Aledo, Antonio (eds.). Turismo residencial y cambio social: Nuevas perspectivas teóricas y empíricas. Alicante: Universidad de Alicante, 375-390.

- (2008). «Tendencias del turismo residencial: El caso del Mediterráneo español». El Periplo Sustentable, 14, 65-87.

- (2009). Turistas que llegan para quedarse: Una explicación sociológica sobre la movilidad residencial. Alicante: Publicaciones de la Universidad de Alicante.

- (2010a). "Opiniones y actitudes ante el turismo residencial en el sur de la Comunidad Valenciana». Pasos: Revista de Turismo y Patrimonio Cultural, 8 (4), 445-461.

- (2010b). "Algo más que buen tiempo: Necesidades de los jubilados europeos en la Costa Blanca». En: Esteban Curiel, Javier de (coord.). Métodos de investigación aplicados al turismo. Madrid: Servicio de Publicaciones Universidad Rey Juan Carlos, 105-117.

Huete, Raquel y Mantecón, Alejandro (2007a). «The role of authenticity in tourism planning: Empirical findings from southeast Spain». Tourism. An International Interdisciplinary Journal, 55 (3), 323-333.

- (2007b). «La búsqueda de la autenticidad y los cambios en la demanda turísticoresidencial». En: López Olivares, Diego (ed.). Turismo en los espacios litorales: Sol, playa y turismo residencial. Valencia: Tirant Lo Blanch, 293-311.

- (2008). "The value of authenticity in residential tourism: The decision-maker's point of view». Tourist Studies, 8 (3), 359-376.

- (2010). «Los límites entre el turismo y la migración residencial. Una tipología». Papers: Revista de Sociología, 95 (3), 781-801.

- (2011). «Más allá del turismo: Movilidad residencial europea y nuevos núcleos urbanos». Boletín de la Asociación de Geógrafos Españoles, 56, 111-128.

Huete, Raquel; Mantecón, Alejandro y Mazón, Tomás (2008a). «Analysing the social perception of residential tourism vevelopment». En: Costa, Carlos y Cravo, Pedro (coords.). Advances in Tourism Research. Aveiro: IASK, 153-161.

- (2008b). «¿De qué hablamos cuando hablamos de turismo residencial?». Cuadernos de Turismo, 22, 101-121. 
- (2009). «La definición del proceso turístico-residencial: El punto de vista de la sociedad receptora». En: LATiEsa, Margarita (ed.). El turismo en el mediterráneo: posibilidades de desarrollo y cohesión. Madrid: Centro de Estudios Ramón Areces, 365-378.

- (2010). «Il turismo residenziale in Spagna nella prospettiva sociologica». En: RomiTA, T. (ed.). Il turismo residenziale. Milán: Franco Angeli, 67-93.

Mantecón, Alejandro (2004). «El discurso político sobre el turismo residencial». En: Álvarez Sousa, Antón (coord.). Turismo, ocio y deporte. La Coruña: Universidade de A Coruña, 205-225.

- (2005). «Residential tourism and political perception: A qualitative, sociological perspective». En: VVAA. The End of Tourism? Mobility and Local Global Connections. Eastbourne: University of Brighton. [CD-ROM]

- (2008a). La experiencia del turismo: Un estudio sociológico sobre el proceso turísticoresidencial. Barcelona: Icaria.

- (2008b). «Procesos de urbanización turística: Aproximación cualitativa al contexto ideológico». Papers: Revista de Sociología, 89, 127-144.

- (2008c). "Actores y relaciones en el sistema turístico-residencial». En: García, Modesto y Schriewer, Klaus (eds.). Ni turistas ni migrantes: Movilidad residencial europea en España. Murcia: Isabor, 311-327.

- (2010). "Tourist modernisation and social legitimation in Spain». International Journal of Tourism Research, 12 (5), 617-625.

- (2011). «El proceso del turismo residencial: Análisis sociopolítico de los discursos públicos desde una perspectiva cualitativa». Empiria: Revista de Metodología de Ciencias Sociales, 21, 17-38.

Mantecón, Alejandro; Aledo, Antonio y Mazón, Tomás (2008). «La insostenibilidad del turismo residencial». En: Lagunas, David (coord.). Antropología y turismo: claves culturales y disciplinares. México: Plaza y Valdés, 185-208

Mantecón, Alejandro; Huete, Raquel y Mazón, Tomás (2009a). «Las urbanizaciones "europeas": Una investigación sobre las nuevas sociedades duales en el Mediterráneo». Scripta Nova: Revista Electrónica de Geografia y Ciencias Sociales, 13, 281-309.

- (2009b). "Tourism dependence and host community perceptions. Notes on the Social Exchange Theory». Tourism \& Management Studies, 5, 25-36.

- (2009c). «Migraciones internacionales de retirados: discursos de la sociedad de acogida ante los estilos de vida de los jubilados europeos residentes en la provincia de Alicante». En: Montoro Gurich, Carolina (ed.). La inmigración internacional: motor de cambios socio-demográficos y territoriales. Pamplona: Ediciones Universidad de Navarra, 293-299.

Martí Ciriquian, Pablo y Ponce Herrero, Gabino (2011). «La expansión urbanística reciente de la costa alicantina, una realidad constatable». En: GozÁlvez PÉrez, Vicente y Marco Molina, Juan Antonio (eds.). Urbanismo expansivo: de la utopía a la realidad. Alicante: Asociación de Geógrafos Españoles, 367-377.

Mazón, Tomás (1987). La urbanización de la Playa de San Juan: un espacio turísticoresidencial. Alicante: I. E. Juan Gil-Albert.

- (1996). El turismo inmobiliario en la provincia de Alicante: análisis y propuestas. Alicante: Patronato Provincial de Turismo. Diputación de Alicante.

- (1999). «Los orígenes de la urbanización en el mundo mediterráneo». En: Oltra, Benjamín (dir.). Culturas, civilizaciones y sociedades mediterráneas. Altea: Fundación Ciencias Sociales y Mundo Mediterráneo.

- (2001). «El modelo hotelero y el extrahotelero: la confusión entre promociones inmobiliarias y turismo». ALQUIBLA: Revista de Investigación del Bajo Segura, 7, 361-382. 
- (2005). Turismo residencial y cambio social: nuevas perspectivas teóricas y empíricas. Alicante: CAM. Obra Social.

- (2006a). «Inquiring on residential tourism: the Costa Blanca case». Tourism and Hospitality Planning \& Development, 3 (2), 89-97.

- (2006b). «El turismo litoral mediterráneo: :políticas turísticas o desarrollo inmobiliario?». En: RodríGuez, Josep Antoni (ed.). Sociología para el futuro. Barcelona: Icaria, 301-310.

Mazón, Tomás y Aledo, Antonio (2004a): «La masificación del turismo residencial: el modelo de Torrevieja». En: Álvarez Sousa, Antón (ed.). Turismo, ocio y deporte. A Coruña: Universidade de A Coruña, 275-286.

- (2004b). "Impact of residential tourism and the destination life cycle theory». En: Pineda, F. D. y Brebbia, Carlos (eds.). Sustainable Tourism. Southampton, Boston: Witpress, 25-36.

- (eds.) (2005a). Turismo residencial y cambio social: Nuevas perspectivas teóricas y empíricas. Alicante: Aguaclara.

- (2005b). «El dilema del turismo residencial: ¿turismo o desarrollo inmobiliario?». En: Mazón, Tomás y Aledo, Antonio (eds.). Turismo residencial y cambio social: Nuevas perspectivas teóricas y empíricas. Alicante: Aguaclara, 13-30.

Mazón, Tomas; Aledo, Antonio y Carreras, Lorenzo (1994). Estudio del Sector Turístico del Municipio de Alicante (1989-1994). Alicante: Departamento de Ciencias Sociales. Universidad de Alicante.

Mazón, Tomás y Aledo, Antonio (dir.) (1996). El turismo inmobiliario en la provincia de Alicante: análisis y propuestas. Alicante: Patronato Provincial de Turismo de la Diputación de Alicante.

Mazón, Tomás; Aledo, Antonio y Martínez, Emilio (1995). «Turismo y cambio». En: Alaminos, Antonio (dir.). Informe sociológico de la provincia de Alicante, 19901995. Alicante: Diputación Provincial, 189-203.

Mazón, Tomás y Huete, Raquel (2005). «Turismo Residencial en el litoral alicantino: los casos de Denia, Altea, Benidorm, Santa Pola y Torrevieja». En: Mazón, Tomás y Aledo, Antonio (eds.). Turismo Residencial y Cambio Social: Nuevas perspectivas teóricas y empiricas. Alicante: Universidad de Alicante, 105-138.

- (2009). "El estilo de vida y los turistas residentes de UE en la provincia de Alicante». En: Latiesa Rodríguez, Margarita; García Fernández, Manuel y Álvarez Sousa, Antón (coords.). Sociología del ocio y del turismo: tipos, planificación y desarrollo. Granada: Universidad de Granada, 279-300.

Mazon, Tomás; Huete, Raquel y Mantecón, Alejandro (coords.) (2009). Turismo, urbanización y estilos de vida: Las nuevas formas de movilidad residencial. Barcelona: Icaria.

- (coords.) (2011). Construir una nueva vida: los espacios del turismo y la migración residencial. Alicante: Milrazones.

Mazón, Tomás; Huete, Raquel; Mantecón, Alejandro y Jorge, María E. (2009). «Legitimación y crisis en la urbanización de las regiones turísticas mediterráneas». En: Mazón, Tomás; Huete, Raquel y Mantecón, Alejandro (coords.). Turismo, urbanización y estilos de vida: las nuevas formas de movilidad residencial. Barcelona: Icaria, 399-412.

Montiel Molina, Cristina (1990). «Desarrollo turístico, promoción inmobiliaria y degradación medioambiental en el municipio de Benitachell (comarca de La Marina)». Investigaciones Geográficas, 8, 113-129.

NARedo, José María (1996). La burbuja inmobiliaria-financiera en la coyuntura económica reciente. Madrid: Siglo Veintiuno. 
Navalón García, María del Rosario (1994). «Notas sobre el régimen urbanístico del medio rural: El tratamiento del suelo no urbanizable en el planeamiento de los municipios turísticos alicantinos». Investigaciones Geográficas, 12, 133-146.

- (1995). Planeamiento urbano y turismo residencial en los municipios litorales de Alicante. Alicante: Instituto de Cultura Juan Gil-Albert.

- (1999). "Caracterización del espacio turístico residencial del litoral valenciano». Boletín de la Asociación de Geógrafos Españoles, 28, 161-178.

- (2001). Agricultura y turismo en la franja costera de la Comunidad Valenciana. Valencia: Bancaixa.

- (2002). «Conflictos por el uso del suelo». En: Romero, Joan; Morales Gil, Alfredo y Vera Rebollo, José Fernando (coords.). Comunidad Valenciana. Barcelona: Ariel, 165-170.

- (2003). «Desarrollo turístico y mercado inmobiliario en la Comarca del Bajo Segura (Alicante)». En: AAVV. La ciudad: nuevos procesos, nuevas respuestas. León: Servicio de Publicaciones de la Universidad de León, 263-274.

Navarro Vera, José Ramón y Ortuño Padilla, Armando (2010). «Impacto de los campos de Golf en Levante» Ciudad y territorio: Estudios territoriales, 163, 35-48.

Obiol Menero, Emilio y Pitarch Garrido, María Dolores (2011). «El litoral turístico valenciano: Intereses y controversias en un territorio tensionado por el residencialismo». Boletín de la Asociación de Geógrafos Españoles, 56, 177-200.

Olcina Cantos, Jorge y Rico Amorós, Antonio Manuel (2005a). «La cuadratura del círculo». En: Romero, Joan y Alberola, Miquel (coords.). Los límites del territorio: El País Valenciano en la encrucijada. Valencia: Universidad de Valencia, 223-226.

- (2005b). «Un crecimiento territorial con pies de barro». En: Romero, Joan y Alberola, Miquel (coords.). Los límites del territorio: El País Valenciano en la encrucijada. Valencia: Universidad de Valencia, 299-303.

Ortiz Noguera, Guadalupe; García Andreu, Hugo; Juan Palmer, María del Pilar y Aledo, Antonio (2007). «Dilemas epistemológicos y éticos de la participación pública en la planificación del turismo residencial». Revista de Turismo y Patrimonio Cultural, 5 (3), 323-329.

Peña Llopis, Juan; Cantó López, María Teresa; Campagne, Daniel y Hernández Hernández, María (2005). "Turismo y agricultura intensiva en la Marina Baixa: Tensiones jurídico-ambientales en zonas de alto impacto turístico». Revista de Derecho Urbanístico y Medio Ambiente, 39 (220), 167-203.

PeÑin Ibáñez, Alberto (1988). «La Marina. Metrópoli rural o campo urbanizado». Revista Urbanismo COAM, 4, 47-54.

Pino, J. del (2003). «Aproximación sociológica a la vivienda secundaria litoral». Scripta Nova: Revista Electrónica de Geografía y Ciencias Sociales, vol. vII, 140 (026).

Quereda SAla, José (1986). "Transformaciones demográficas y paisajísticas en la Marina Baixa». Cuadernos de Geografía, 39-40, 345-352.

Rodríguez, Vicente; Casado, María de los Ángeles y Hubber, Andreas (eds.) (2005). La migración de europeos retirados en España. Madrid: CSIC.

SALORT VIVES, Salvador (1989). «El turismo como factor diferenciador en el mercado de la tierra: Los modelos de El Verger y Els Poblets». Investigaciones Geográficas, 7, 237-249.

Torres Alfosea, Francisco José y Hernández Hernández, María (2006). «Previsiones de consumo de agua para uso residencial en la Comunidad Valenciana». En: Demanda y consumo de agua en el dominio mediterráneo. Mallorca: Fundación Ramón Areces y Club Última Hora, 50-54. 
Vera Rebollo, José Fernando (1984). «Mutaciones espaciales producidas por el turismo en el municipio de Torrevieja». Investigaciones Geográficas, 2, 115-139.

- (2000). "El modelo turístico de la Marina Alta: Apuntes para una nueva etapa desde la sostenibilidad como referencia». Investigaciones Geográficas, 4, 133-142.

- (2005). «El auge de la función residencial en destinos turísticos del litoral mediterráneo: entre el crecimiento y la renovación». Papers de Turisme, 37-38, 95-114.

- (2008). «Viviendas de ocupación no habitual». En: Atlas Nacional de España: Turismo en espacios rurales y naturales. Madrid: Instituto Geográfico Nacional.

\section{Planificación y gestión de los recursos y las demandas}

II.1. Insuficiencia de recursos y conflictos por el acceso al recurso hidrico. Trascendencia del recurso hidrico

BRu Ronda, Concepción (1984). «Nuevas formas de tenencia de la propiedad del agua en el Campo de Alicante». Investigaciones Geográficas, 2, 105-114.

- (1987). «Notas acerca del desequilibrio espacial de las disponibilidades hídricas en la Comunidad Valenciana». Investigaciones Geográficas, 5, 117-128.

- (1989a). "La escasez hídrica alicantina y las acciones de regulación». En: MarTín Mateo, Ramón (ed.). El reto del agua. Alicante: Instituto de Cultura Juan Gil Albert, 167-180.

- (1989b). «Un caso paradigmático en el proceso evolutivo de la economía hídrica alicantina: la comarca del Campo de Alicante». Estudios Geográficos, 49 (190), 29-55.

Bengoechea Morancho, Aurelia y Fuertes Eugenio, Ana María (2001). «El agua como factor limitativo del desarrollo regional en la Comunidad Valenciana». Revista del Instituto de Estudios Económicos, 4, 351-366.

Gil Olcina, Antonio (1987). «Propiedad y valor de las aguas del Bajo Vinalopó». En: Homenaje al profesor Juan Torres Fontes. Murcia: Universidad de Murcia. Secretariado de Publicaciones, vol. 1, 647-659.

- (1993a). La propiedad de aguas perennes en el sureste ibérico. Alicante: Universidad de Alicante.

- (1993b). "La demanda de agua en territorio valenciano». Investigaciones Geográficas, $11,7-22$.

Gil Olcina, Antonio y Rico Amorós, Antonio Manuel (2001). «Demanda y disponibilidad de agua». En: Gil Olcina, Antonio y Gómez Mendoza, Josefina (eds.). Geografía de España. Barcelona: Ariel, 441-454.

- (2007). El problema del agua en la Comunidad Valenciana. Valencia: Generalitat Valenciana.

Hernández Hernández, María; Rico Amorós, Antonio Manuel y Juárez Sánchez Rubio, Cipriano (2010). "Conflicts over water and land use on the coastline of the region of Valencia: agriculture versus the urban city». En: BrebBia, Carlos; Hernández, S. y TiezzI, Enzo (eds.). The sustainable city: Urban regeneration and sustainability. Southampton: WIT Press, 405-417.

Juárez SÁnChez Rubio, Cipriano (1993-1994). «Infraestructura hidráulica y crecimiento económico en la Marina Baja». Revista Sharq Al-Andalus, 10-11, 453-465.

- (2000). "El papel de la oferta de agua en el desarrollo productivo de la Vega Baja del Segura (Alicante)». Alquibla: Revista de Investigaciones del Bajo Segura, 6, 99-118. 
- (2006). «Escasez de agua y transformación económica del sistema territorial de Aspe: Retos y oportunidades». En: Estévez Rubio, Antonio; Andreu Rodes, José Miguel; García Sánchez, E.; Juárez Sánchez Rubio, Cipriano; Mataix, Jorge Juan y Pulido Bosch, Antonio. (eds.). El acuifero cuaternario de Aspe: Contexto socioeconómico, hidrogeológico y medioambiental. Alicante: Universidad de Alicante, 21-69.

Juárez Sánchez Rubio, Cipriano y Bru Ronda, Concepción (1989). El reto del agua. Alicante: Instituto de Cultura Juan Gil-Albert.

Juárez Sánchez Rubio, Cipriano; Hernández Hernández, María y Rico Amorós, Antonio Manuel (2010). "Guarantee of water availability and change in land use in the southern coastal area of the community of Valencia (Spain)». En: BrebBia, Carlos; Hernández, S. y TiezzI, Enzo (eds.). The sustainable city: Urban regeneration and sustainability. Southampton: WIT Press, 393-404.

Morales Gil, Alfredo y Gil Olcina, Antonio (2004). «El agua, elemento esencial, escaso y poco valorado». Apuntes de Medio Ambiente, 4, 14-19.

Olcina Cantos, Jorge y Rico Amorós, Antonio Manuel (2002). «Sobreexplotación de recursos de agua y conflictos de uso en el País Valenciano». Quaderns Agroambientals, 2, 9-37.

Rico Amorós, Antonio Manuel (1997). Recursos hidricos y desarrollo regional en la Comunidad Valenciana. Alicante: Universidad de Alicante.

- (1998). Agua y desarrollo en la Comunidad Valenciana. Alicante: Universidad de Alicante.

- (2000). «Los recursos de agua». En: Gil Olcina, Antonio (dir.). Cartografía temática de las tierras alicantinas. Alicante: Servicio de Publicaciones de la Universidad de Alicante.

- (2001). "Los recursos de agua». En: Romero, Joan; Morales, Alfredo y Vera, José Fernando (coords.). La periferia emergente: La Comunidad Valenciana en la Europa de las regiones. Barcelona: Ariel, 421-461.

- (2002). «Insuficiencia de recursos hídricos y competencia de usos en la Comunidad Valenciana». Boletín de la Asociación de Geógrafos Españoles, 33, 23-50.

Rico Amorós, Antonio Manuel y Hernández Hernández, María (2007). «Ordenación del territorio, escasez de recursos hídricos, competencia de usos e intensificación de las demandas urbano-turísticas en la Comunidad Valenciana». Documents d'Anàlisi Geogràfica, 51, 79-109.

Ruiz Canales, Antonio y Melián Navarro, Amparo (2006). "Actividad agraria en las comarcas del sur de Alicante y competencia con otros sectores por los usos del agua y del suelo». Papeles de Geografía, 43, 105-119.

SAntafé Martínez, José María (1989). «Recursos y usos del agua en la Comunidad Valenciana. Corrección de desequilibrios». En: AAVV. El agua en la Comunidad Valenciana. Valencia: COPUT, 41-59.

\section{II.2. Planificación y gestión de los recursos y de la demanda: recursos nuevos y convencionales}

Ayanz López Cuervo, Juan José y Plaza Martínez, A. (2009). «Importancia del trasvase Tajo-Segura en el abastecimiento del Sureste Español». En: Melgarejo Moreno, Joaquín (dir.). El trasvase Tajo-Segura: repercusiones económicas, sociales y ambientales en la cuenca del Segura. Alicante: CAM, 309-341.

Bautista Marín, J. (1992). «Del Plan de Mejora y Ampliación de Riegos de Levante al aprovechamiento conjunto Tajo-Segura». En: Gil Olcina, Antonio y Mora- 
LES GiL, Alfredo (eds.). Hitos históricos de los regadíos españoles. Madrid: MAPA, 365-404.

Box Amorós, Margarita (1988). «El trasvase Tajo-Segura». En: Gil Olcina, A. y Morales Gil, A. (eds.). Demanda y economía del agua en España. Alicante: Universidad de Alicante, 277-286.

Box Amorós, Margarita y Morales Gil, Alfredo (1992). "Consecuencias socioeconómicas y medioambientales de los trasvases de agua en España (1978-1992)». Investigaciones Geográficas, 10, 25-36.

BRu Ronda, Concepción (1995). «Las grandes realizaciones hidráulicas: de la Mancomunidad de los Canales del Taibilla al aprovechamiento conjunto Tajo-Segura». En: Gil Olcina, Antonio y Morales Gil, Alfredo (eds.). Planificación Hidráulica en España. Alicante: Universidad de Alicante, 283-306.

Cánovas Cuenca, Juan y Martínez Vicente, David (2009): «La desalación de aguas en la Región del Mediterráneo». En: AAVV. Desalación de aguas: Aspectos tecnológicos, medioambientales, jurídicos y económicos. Murcia: Fundación Instituto Euromediterráneo del Agua, 477-491.

Carrillo de la Orden, Isidoro (2002). «El abastecimiento urbano. La Mancomunidad de los Canales del Taibilla». En: CÁnovas, Juan y Melgarejo, Joaquín (eds.). La Confederación Hidrográfica del Segura, 1926-2001. 75 Aniversario. Murcia: MIMAM.

Carrillo de la Orden, Isidoro y Mirón López, Luis María (2004). «La Mancomunidad de los Canales del Taibilla». En: Gil Olcina, A. (dir.). La cultura del agua en la cuenca del Segura. Murcia: Fundación Caja Murcia, 199-220.

Claver Valderas, José Manuel (2002). «Situación actual del trasvase Tajo-Segura». En: Cánovas, Juan y Melgarejo, Joaquín (eds.). La Confederación Hidrográfica del Segura, 1926-2001. 75 Aniversario. Murcia: MIMAM, 217-260-

Consorcio de Aguas de la Marina Baja (2009). Reutilización de aguas depuradas en la Marina Baja (Alicante). Valencia: COPUT.

Ezcurra Cartagena, Joaquín (2002). «El trasvase Tajo-Segura». En: CÁnovas, Juan y Melgarejo, Joaquín (eds.). La Confederación Hidrográfica del Segura, 1926-2001. 75 Aniversario. Murcia: MIMAM, 261-278.

- (2004). "El trasvase Tajo-Segura: 25 años de explotación». En: Gil Olcina, Antonio (dir.). La cultura del agua en la cuenca del Segura. Murcia, Cajamurcia, 515-546.

Gil Olcına, Antonio (1992). «Desequilibrios hidrográficos en España y trasvases a la vertiente mediterránea: utopías y realidades». Investigaciones Geográficas, $10,7-22$.

- (1995). «Desequilibrios de recursos hídricos y planteamientos de trasvases en territorio valenciano». En: Gil Olcina, Antonio y Morales Gil, Alfredo (eds.). Planificación Hidráulica en España. Alicante: Fundación Caja del Mediterráneo, 399-430.

- (1999). «Redistribución de recursos hídricos propios y demanda de foráneos en territorio valenciano». En: AAVV. Professor Joan Vilà Valentí: el seu mestratge en la geografia universitària. Barcelona: Universitat de Barcelona, 985-998.

- (2010). «Optimización de recursos hídricos y armonización de sus usos: el Consorcio de Aguas de la Marina Baja». Investigaciones Geográficas, 51, 165-183.

Gil Olcina, Antonio y Rico Amorós, Antonio Manuel (2008). Políticas del agua II. Impronta territorial del Plan de Mejora y Ampliación de los Riegos de Levante (19331985). Murcia: ESAMUR. 
JuÁrez SÁnchez Rubio, Cipriano (1991). Planificación hidrológica y desarrollo económico: El trasvase Tajo-Segura. Alicante: Instituto de Cultura Juan Gil Albert.

- (1993). «La depuración del agua en la Mancomunidad de l'Alacantí: Mejora del medio ambiental, repercusión económica y ordenación territorial». Estudios Geográficos, 54 (213), 633-654.

Juárez Sánchez Rubio, Cipriano y Gómez Fernández Cuesta, José Antonio (1993). «La gestión del agua en el área de Alicante». Revista Canelobre, 27, 45-52.

Melgarejo Moreno, Joaquín (2000). «Balance económico del trasvase Tajo-Segura». Investigaciones Geográficas, 24, 69-95.

- (2004). «La planificación y la concreción del PHN en la provincia de Alicante». En: Melgarejo Moreno, Joaquín (ed.). Repercusiones socioeconómicas del Plan Hidrológico Nacional en la provincia de Alicante. Alicante: COEPA, 25-63.

- (dir.) (2009). El trasvase Tajo-Segura: Repercusiones económicas, sociales y ambientales en la cuenca del Segura. Alicante: CAM.

Morales GiL, Alfredo (1987). "Aprovechamiento conjunto Tajo-Segura y otros trasvases». El Campo, 103, 47-50. [Monográfico de la Comunidad Valenciana]

- (1988). «Trasvases de recursos hídricos en España». En: Gil Olcina, Antonio y Morales Gil, Alfredo (eds.). Demanda y economía del agua. Alicante: Universidad de Alicante, 239-254.

- (1995). "Déficit de agua y demanda de transferencias en la cuenca del Segura». En: Gil Olcina, Antonio y Morales Gil, Alfredo (eds.). Planificación Hidráulica en España. Murcia: Fundación Caja del Mediterráneo, 379-398.

- (2002). «Un modelo de eficiencia en el abastecimiento urbano de agua: La Mancomunidad de Canales del Taibilla». En: Cánovas, Juan y Melgarejo, Joaquín (eds.). La Confederación Hidrográfica del Segura 1926-2001. 75 Aniversario. Madrid: Ministerio de Medio Ambiente, 289-310.

Morales Gil, Alfredo; Rico Amorós, Antonio Manuel y Hernández HernánDEZ, María (2005). "El trasvase Tajo-Segura». Observatorio Medioambiental, 8, 73-110.

Morales Gil, Alfredo y Vera Rebollo, José Fernando (1989a). La Mancomunidad de los Canales del Taibilla: Influencia de un gran sistema de abastecimiento público de aguas en el desarrollo económico-territorial. Alicante: Academia Alfonso X el Sabio.

- (1989b). «Ordenación y gestión de recursos hídricos en un ámbito subárido: el abastecimiento de los municipios integrados en la Mancomunidad de los Canales del Taibilla». Investigaciones Geográficas, 7, 51-68.

Olcina Cantos, Jorge (2002a). «Planificación hidrológica y recursos de agua no convencionales en España». En: Gil Olcina, Antonio y Morales Gil, Alfredo (eds.). Insuficiencia hídrica y Plan Hidrológico Nacional. Alicante: Universidad de Alicante y CAM, 69-130.

- (2002b). «Nuevos retos de depuración y desalación de aguas en España». Investigaciones Geográficas, 27, 5-34.

Olcina Cantos, Jorge y Moltó Mantero, Enrique (2010). «Recursos de agua no convencionales en España: estado de la cuestión». Investigaciones Geográficas, 51, 131-163.

Olcina Cantos, Jorge y Rico Amorós, Antonio Manuel (1998). «Recursos de agua no convencionales en España: depuración y desalación». En: Gil Olcina, Antonio y Morales Gil, Alfredo (eds.). Los usos del agua en España. Alicante: Caja de Ahorros del Mediterráneo, 203-252. 
- (2001). «La gestión colectiva de las aguas subterráneas en tierras alicantinas». En: Hernández Mora, Nuria y Llamas, Ramón (eds.). La economía del agua subterránea y su gestión colectiva. Madrid: Mundiprensa, 475-533.

- (2006). «La Mancomunidad de los Canales del Taibilla: un ejemplo de cooperación municipal surgido de una necesidad». En: FARINOS I DASI, Joaquín y RoMERo González, Joan (cords.). Gobernanza territorial en España: claroscuros de un proceso a partir del estudio de casos. Valencia: Universidad de Valencia, 347-374.

Prats Rico, Daniel y Melgarejo Moreno, Joaquín (2006). Desalación y reutilización de aguas: Situación en la provincia de Alicante. Alicante: Generalitat Valenciana y COEPA.

Rico Amorós, Antonio Manuel (1996). «Depuración y reutilización de aguas residuales en el litoral alicantino». Papeles de Geografía, 23-24, 245-262.

- (2002). «Escasez de recursos de agua y planteamiento de trasvases en la provincia de Alicante: la transferencia Júcar-Vinalopó». En: Gil Olcina, Antonio y Morales Gil, Alfredo (eds.). Insuficiencias hidricas y Plan Hidrológico Nacional. Alicante: CAM, 407-477.

- (2004). «Aguas desaladas». En: Gil Olcina, Antonio (dir.). La cultura del agua en la cuenca del Segura. Murcia: Cajamurcia, 567-590.

Rico Amorós, Antonio Manuel y Olcina Cantos, Jorge (2003). «Politiques de l’eau en milieu méditerranéen: Le cas de la péninsule Ibérique». Collection de la Casa de Velázquez, 82, 89-102.

- (2004). «El abastecimiento de agua potable en la Marina Baja (Alicante): Un ejemplo de complementariedad entre usos agrarios y urbano-turísticos». En: AAVV. Historia, clima y paisaje. Valencia: Universidad de Valencia, 551-567.

Rico Amorós, Antonio Manuel; Olcina Cantos, Jorge; Paños Callado, Vicente y Baños Castiñeira, Carlos (1998). Depuración, desalación y reutilización de aguas en España. Barcelona: Oikos-Tau.

SAuri, David; Olcina, Jorge y Rico, Antonio Manuel (2007). «The March towards Privatisation? Urban water supply and salinitation in Spain». Journal of Comparative Social Welfare, 23 ( 2), 131-139.

Torregrosa Martí, María Teresa (2009). La gestión del agua en la Marina Baja (Alicante). Valencia: Edición de las Cortes Valencianas.

Vera Rebollo, José Fernando (2002). «Transferencia de recursos y demandas turísticas». En: Gil Olcina, Antonio y Morales Gil, Alfredo (eds.). Insuficiencias hidricas y Plan Hidrológico Nacional. Alicante: Universidad de Alicante y CAM, 197-200.

\section{Metodología}

Aledo Tur, Antonio; García Andreu, Hugo y Ortiz Noguera, Guadalupe (2010). "Análisis de mapas causales de impactos del turismo residencial». Empiria: Revista de Metodología de Ciencias Sociales, 20, 61-86.

Aledo Tur, Antonio y Mazón, Tomás (1998). «Análisis y metodología para el estudio del sector turístico de una comarca: El caso del Bajo Segura (Alicante)». Estudios Turísticos, 137, 55-66.

Aledo Tur, Antonio; García Andreu, Hugo; Ortiz Noguera, Guadalupe y Juan Palmer, María del Pilar (2008). «Estrategias de participación pública en la planificación de municipios turístico-residenciales». En: AAVV. Las administraciones públicas y las empresas turisticas ante el reto de la sostenibilidad. AECIT. [Recurso electrónico] 
Instituto Universitario de Geografía (1996). Programa de revitalización de municipios con turismo residencial. Alicante: IUG-Universidad de Alicante y Diputación Provincial de Alicante.

JuÁrez SÁnchez Rubio, Cipriano (2004). «Sistemas de indicadores de sostenibilidad y desarrollo turístico: aplicación a la comarca del Bajo Segura (Alicante)». Investigaciones Geográficas, 33, 17-38.

- (2008). «Indicadores hídricos de sostenibilidad y desarrollo turístico y residencial en la Costa Blanca (Alicante)». Boletín de la Asociación de Geógrafos Españoles, 213-243.

Membrado Tena, Joan Carles (2011). "Cartografía de urbanismo expansivo valenciano según SEIOSE». En: GozÁlvez Pérez, Vicente y Marco Molina, Juan Antonio (eds.). Urbanismo expansivo: de la utopía a la realidad. Alicante: Asociación de Geógrafos Españoles, 415-414.

Rico Amorós, Antonio Manuel (1997). «Metodología y fuentes aplicadas a una investigación sobre sistemas de abastecimiento de agua públicos en municipios costeros de la provincia de Alicante (España)». En: Joliveau, Tierry y Bethemont, Jacques

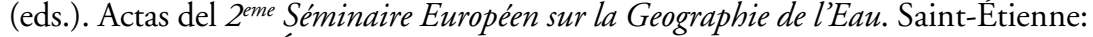
Université de Saint-Étienne, 133-137.

Torregrosa Martí, María Teresa y Sevilla Jiménez, Martín (2009). «La integración del medio físico en la gestión integrada de recursos hídricos de la Marina Baja (Alicante)». Investigaciones Geográficas, 48, 39-76.

Torres Alfosea, Francisco José (1995). Aplicación de un sistema de información geográfica al estudio de un modelo de desarrollo local: Crecimiento urbano-turistico de Torrevieja (1956-1993). Alicante: Universidad de Alicante.

Vera Rebollo, José Fernando (coord.) (2001). Planificación y gestión del desarrollo turístico sostenible: Propuesta para la creación de un sistema de indicadores. Alicante: Universidad de Alicante.

- (2004). «Desarrollo turístico y control de crecimiento: utilidades de la capacidad de carga». En: Pardellas de Blas, Xulio Xose. Potencial turístico de territorios periféricos. Vigo: Servizo de Publicacións da Universidade de Vigo, 87-108.

- (2006). "Agua y modelos de desarrollo turístico: la necesidad de nuevos criterios para la gestión de los recursos». Boletín de la Asociación de Geógrafos Españoles, 42, $155-178$.

- (2008). Diagnóstico técnico sobre funciones urbanas y desarrollo territorial en Denia: Aplicaciones de un sistema de indicadores. Valencia: Universidad de Valencia.

Vera Rebollo, José Fernando; Baños Castiñeira, Carlos Javier y Jiménez RodríGUEZ, Arturo (1995). «Elaboración de un plan para la cualificación de asentamientos en municipios consolidados por el turismo». Investigaciones Geográficas, 14, 31-58.

Vera Rebollo, José Fernando e Ivars Baidal, Josep Antoni (2003a). «Sistema de indicadores aplicado a la planificación y gestión del desarrollo turístico sostenible». En: Valdés Peláez, Luis; Pérez Fernández, José Manuel y Valle Tuero, Eduardo del (coords.). Experiencias públicas y privadas en el desarrollo de un modelo de turismo sostenible. Fundación Universidad de Oviedo, 105-129.

- (2003b). "Measuring sustainability in a Mass Tourism Destination: pressures, perceptions and policy responses in Torrevieja, Spain». Journal of Sustainable Tourism, $11(2 \& 3), 181-203$. 